\title{
Transformation of a Norbornadiene Unit to Ethylenylcyclopentene Requiring Cooperation Between Boron and Rhodium Centers
}

\author{
Angelo Iannetelli, ${ }^{\dagger}$ Rosenildo C. Da Costa, ${ }^{\dagger}$ Alan J. Guwy, ${ }^{\dagger}$ Graham J. Tizzard, ${ }^{\ddagger}$ Simon J. Coles, ${ }^{\ddagger}$ and \\ Gareth R. Owen ${ }^{\dagger *}$
}

${ }^{\dagger}$ School of Applied Sciences, University of South Wales, Pontypridd, CF37 4AT, UK.

‡UK National Crystallography Service, University of Southampton, Highfield, Southampton, SO17 1BJ, UK.

\begin{abstract}
The synthesis of the lithium salt of a bis-substituted borohydride anion containing a phenyl substituent and a 2-mercaptopyridyl unit (mp) is reported herein. This salt has been used as a pro-ligand for the synthesis of $\operatorname{rhodium}(\mathrm{I}) \operatorname{complex},\left[\mathrm{Rh}\left\{\kappa^{3}-\right.\right.$ $\left.\left.H, H, S-\mathrm{H}_{2} \mathrm{~B}(\mathrm{Ph})(\mathrm{mp})\right\}(\mathrm{NBD})\right](\mathbf{1})$ (where $\mathrm{NBD}=2,5$-norbornadiene). The new boron-based ligand coordinates to the rhodium center via the thione donor and the two $\mathrm{B}-\mathrm{H}$ bonds of the $\mathrm{BPhH}_{2}$ unit, with a dihydroborate motif. Reaction of complex 1 with two equivalents of triphenylphosphine leads to an unprecedented rearrangement and transfer of the former norbornadiene ligand to the boron center. The transformation occurs via an initial hydride migration from boron to the rhodium center followed by a hydroboration of one of the double bonds. Finally, a ring opening process occurs involving both boron and rhodium centers leading to an unusual boron bound ethylenylcyclopentene unit. The product of this reaction was confirmed as $\left[\mathrm{Rh}\left\{\eta^{1}-S, \eta^{2}-B, C\right.\right.$ $\left.\mathrm{B}(\mathrm{Ph})\left(\mathrm{CHCH}_{2}\left(\mathrm{C}_{5} \mathrm{H}_{7}\right)(\mathrm{mp})\right\}\left(\mathrm{PPh}_{3}\right)_{2}\right](2)$. The net result of these transformations is the incorporation of the two hydrogen atoms from the secondary borohydride ligand $\left[\mathrm{BPhH}_{2}(\mathrm{mp})\right]^{-}$into the former norbornadiene unit. The endpoint positions of these hydrogen atoms were confirmed by deuterium labelling experiments. Complex 2 was further reacted with carbon monoxide to generate $\left[R h\left\{\eta^{1}-S, \eta^{2}-\right.\right.$ B, C-B $\left.(\mathrm{Ph})\left(\mathrm{CHCH}_{2}\left(\mathrm{C}_{5} \mathrm{H}_{7}\right)(\mathrm{mp})\right\}(\mathrm{CO})\left(\mathrm{PPh}_{3}\right)\right]$ (3) via ligand substitution. The new ligand and the three complexes, $\mathbf{1}, \mathbf{2}$ and $\mathbf{3}$, have been characterized by spectroscopic techniques as well as by X-ray crystallography. Detailed characterization of $\mathbf{2}$ and $\mathbf{3}$ revealed an unusual $\eta^{2}-B, C$ coordination mode within these complexes. Further studies have demonstrated that complexes $\mathbf{2}$ and $\mathbf{3}$ react with hydrogen gas (or dimethylamine borane as a source of $\mathrm{H}_{2}$ ) to generate the hydrogen addition products involving the unprecedented activation of the Rh- $\eta^{2}-B, C$ motif. Complexes $\mathbf{2}$ and $\mathbf{3}$ were further found to be active catalysts for the hydrogenation of olefins and the dehydrogenation of dimethylamine borane.
\end{abstract}

\begin{abstract}
Introduction
"Ligand cooperation" can be defined as systems in which both metal and ligand centers work together to facilitate transformations that would not occur by using just one of these centers. Transformations involving cooperation between ligands and transition metal centers have become a major focus of research over the past decade or so.$^{1-3}$ In particular, those involving the transfer and storage of hydrogen atoms have been a major feature, where either a "protic" species or "hydridic" species is transferred between a metal center and a position within a pre-coordinated ligand. One strategy for the mobility of hydrogen within the coordination sphere of transition metal complexes has employed borane or borohydride functional groups. The latter acts as a metal-hydride source and leads to the formation of Z-type borane complexes. ${ }^{2}$ There are a range of examples exhibiting low energy ${ }^{2 \mathrm{f}}$ and reversible hydride migrations ${ }^{3}$ between boron and metal centers. There are, to a much lesser extent, examples of transfers involving other functional groups such as methyl or phenyl. ${ }^{4,5}$ In a recent example published by ourselves we reported a system exhibiting multiple migrations between boron and transition metal centers. ${ }^{5}$ This presented the activation of a norbornadiene moiety within a rhodium transition metal complex containing a mono-substituted borohydride ligand. In this case, the norbornadiene unit was transferred to the boron center via a formal hydroboration step (Scheme 1). We found that this transformation did not occur via an intermolecular process. A mechanism was proposed in which hydride migration
\end{abstract}

from boron to the rhodium center had occurred, followed by migratory insertion of the double bond into the resulting rhodium-hydride bond. In the final step, a migration of the newly formed norbornenyl (nbe) unit from the rhodium to the boron center occurred. These multiple migration steps appeared to transpire as a result of cooperation between the rhodium and boron centers. This also provided the first reported example of hydride migration from boron to metal center in the case of a mono-substituted borohydride ligand.

Scheme 1. Formal hydroboration of one of the double bonds of the norbornadiene leading to a norbornenyl group at boron via a series of migrations between boron and rhodium centers ${ }^{\mathrm{a}}$

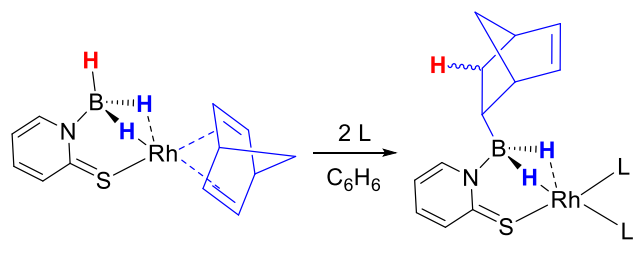

${ }^{\text {a }} \mathrm{L} / \mathrm{L}=\mathrm{CO} / \mathrm{CO}$ or $\mathrm{CO} / \mathrm{PR}_{3}$ where the $\mathrm{PR}_{3}$ ligand is trans to the $\mathrm{BH}_{2}$ unit

In order to understand the processes involved in these migrations further, we developed new derivative compounds and tested their reactivity in a similar manner. It was of interest to us to explore the 
impact of a higher substitution pattern around the boron center. Herein, we wish to report our latest results in which we have found an unprecedented ring opening transformation on norbornadiene involving direct cooperation between boron and rhodium centers. These newly formed products contain a highly novel borata-alkene unit which binds to the rhodium centers via a $\eta^{1}-S, \eta^{2}-B, C$ coordination mode. We further demonstrate the ability of this unit to activate molecular hydrogen across the $\mathrm{BC}$ bond. Finally, we also report the catalytic application of these complexes for hydrogenation and dehydrogenation transformations.

\section{Results and Discussion}

The synthesis of mono-substituted borohydride ligand, $\mathrm{Na}\left[\mathrm{H}_{3} \mathrm{~B}(\mathrm{mp})\right]$ (where $\mathrm{mp}=2$-mercaptopyridyl) was reported by ourselves in a recent publication. ${ }^{5}$ A straightforward adaptation of this procedure was utilized in the synthesis of new ligand, $\mathrm{Li}\left[\mathrm{H}_{2} \mathrm{~B}(\mathrm{Ph})(\mathrm{mp})\right]$ (Scheme 2). The solid precursors $\mathrm{Li}\left[\mathrm{H}_{3} \mathrm{~B}(\mathrm{Ph})\right]$ and 2-mercaptopyridine were added to a Schlenk flask in a 2:1 molar ratio (an excess of the phenylborohydride). An immediate reaction occurred upon addition of THF solvent as observed by the release of hydrogen gas from the mixture. After approximately $5 \mathrm{~min}$, the effervescence subsided. The reaction mixture was monitored by ${ }^{11} \mathrm{~B}$ NMR spectroscopy. After $1 \mathrm{~h}$, three boron containing species were observed at $-26.7 \mathrm{ppm}$ (quartet) corresponding to unreacted $\left[\mathrm{H}_{3} \mathrm{~B}(\mathrm{Ph})\right]^{-}$, at $-15.5 \mathrm{ppm}$ (broad triplet) corresponding to a $\left[\mathrm{H}_{2} \mathrm{~B}(\mathrm{Ph})\right]^{-}$unit of an intermediate species and at $-7.4 \mathrm{ppm}$ (triplet) identified as the targeted $\left[\mathrm{H}_{2} \mathrm{~B}(\mathrm{Ph})(\mathrm{mp})\right]^{-}$product. A ${ }^{11} \mathrm{~B}$ NMR spectrum of the reaction mixture after $48 \mathrm{~h}$ confirmed the consumption of the intermediate species and a spectrum which revealed only $\left[\mathrm{H}_{2} \mathrm{~B}(\mathrm{Ph})(\mathrm{mp})\right]^{-}$and the excess $\left[\mathrm{H}_{3} \mathrm{~B}(\mathrm{Ph})\right]^{-}$reagent used in the reaction. A similar intermediate species was observed in the synthesis of $\mathrm{Na}\left[\mathrm{H}_{3} \mathrm{~B}(\mathrm{mp})\right]$ which was characterized as the isomer containing a boron-sulfur bond. ${ }^{5}$ Following its completion, isolation of the targeted product from the reaction mixture was readily achieved by removal of all volatiles and washing the residue with toluene. The pure solid product was isolated as a fine white powder with a yield of $72 \%$. It should be noted that the solid was found to be hygroscopic.

Scheme 2. Synthesis of $\mathrm{Li}\left[\mathrm{H}_{2} \mathrm{~B}(\mathrm{Ph})(\mathrm{mp})\right]$

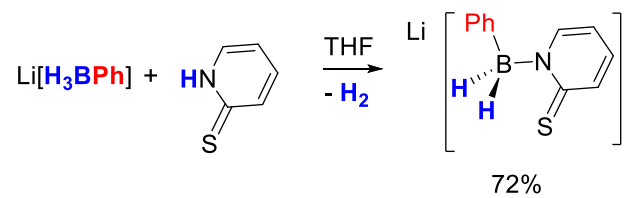

The isolated salt, $\mathrm{Li}\left[\mathrm{H}_{2} \mathrm{~B}(\mathrm{Ph})(\mathrm{mp})\right]$ was characterized by NMR spectroscopy using $\mathrm{CD}_{3} \mathrm{CN}$ as solvent. The ${ }^{11} \mathrm{~B}$ NMR spectrum confirmed the presence of a $\left[\mathrm{BH}_{2}\right]^{-}$unit as a triplet resonance centered at $-6.3 \mathrm{ppm}\left({ }^{1} \mathrm{~J}_{\mathrm{BH}}=92 \mathrm{~Hz}\right)$. This signal appeared as a singlet in the corresponding ${ }^{11} \mathrm{~B}\left\{{ }^{1} \mathrm{H}\right\}$ NMR experiment. Confirmation of the presence of both phenyl and 2-mercaptopyridyl units was obtained in the ${ }^{1} \mathrm{H}$ NMR spectrum. This exhibited a total of seven aromatic signals; three accounting for the 5 protons of the phenyl group and four corresponding to the four environments of the 2mercaptopyridyl ring. Also present within the ${ }^{1} \mathrm{H}$ NMR spectrum was a very broad quartet resonance centered at $2.22 \mathrm{ppm}$, typical of protons attached to a quadrupolar boron center. This became more clear in the corresponding ${ }^{1} \mathrm{H}\left\{{ }^{11} \mathrm{~B}\right\}$ NMR experiment in which this resonance appeared as a sharp singlet integrating for 2 protons with respect to the aromatic signals. This further confirmed the presence of the $\mathrm{BH}_{2}$ unit within the ligand. Full assignment of each signal in the ${ }^{1} \mathrm{H}$ NMR and the corresponding ${ }^{13} \mathrm{C}\left\{{ }^{1} \mathrm{H}\right\}$ NMR spectra was pos- sible via a series of correlation experiments (see Experimental Section). Finally, the $\left[\mathrm{BH}_{2}\right]$ unit was also observable by ATR-FT-IR spectroscopy where the $\mathrm{B}-\mathrm{H}$ bonds exhibited a broad absorption band at $2263 \mathrm{~cm}^{-1}$.

With the new ligand in hand, we set out to synthesize new group nine complexes. Rhodium complex, $\left[\mathrm{Rh}\left\{\kappa^{3}-S, H, H-\right.\right.$ $\left.\left.\mathrm{H}_{2} \mathrm{~B}(\mathrm{Ph})(\mathrm{mp})\right\}(\mathrm{NBD})\right]$ (1) was readily prepared from the reaction between the $\mathrm{Li}\left[\mathrm{H}_{2} \mathrm{~B}(\mathrm{Ph})(\mathrm{mp})\right]$ and one half of an equivalent of the rhodium dimer precursor, $[\mathrm{RhCl}(\mathrm{NBD})]_{2}$ according to established procedures (Scheme 3). ${ }^{6}$ The resulting product was isolated as a spectroscopically pure orange solid in excellent yield. The ${ }^{11} \mathrm{~B}$ NMR spectrum of 1 revealed a single peak centered at $1.0 \mathrm{ppm}$ as a triplet resonance $\left({ }^{1} \mathrm{~J}_{\mathrm{BH}}=62 \mathrm{~Hz}\right)$ confirming that the presence of the $\mathrm{BH}_{2}$ unit in the product. The downfield chemical shift with respect to free ligand is consistent with its coordination to the rhodium center. ${ }^{7}$ The reduction in the ${ }^{1} \mathrm{~J}_{\mathrm{BH}}$ coupling constant in the complex is also suggestive of a significant degree of interaction between the $\mathrm{BH}_{2}$ units and the metal center $(c f .92 \mathrm{~Hz}$ for the ligand with $62 \mathrm{~Hz}$ for $\mathbf{1}$ ). This strong interaction is also evident from the solid state infrared spectrum of 1 where a band at $1827 \mathrm{~cm}^{-1}$ is observed for the $\mathrm{BH}_{2}$ unit coordinated to the rhodium center. ${ }^{8}$ The ${ }^{1} \mathrm{H}$, ${ }^{1} \mathrm{H}\left\{{ }^{11} \mathrm{~B}\right\}$ and ${ }^{13} \mathrm{C}\left\{{ }^{1} \mathrm{H}\right\}$ NMR spectra were also fully consistent with the expected product. Of particular note was the presence of a doublet signal at $-1.59 \mathrm{ppm}$ in the ${ }^{1} \mathrm{H}\left\{{ }^{11} \mathrm{~B}\right\}$ NMR spectrum which revealed a small coupling constant to rhodium center $\left({ }^{1} \mathrm{~J}_{\mathrm{RhH}}=2.0 \mathrm{~Hz}\right)$. This corresponds to the $\mathrm{BH}_{2}$ protons which are shifted upfield upon coordination. The data confirmed a symmetrical and strong coordination of the $\mathrm{BH}_{2}$ unit in solution. The magnitude of the ${ }^{1} \mathrm{~J}_{\mathrm{RhH}}$ coupling constant however, was notable in comparison to the related complex $\left[\mathrm{Rh}\left\{\kappa^{3}-H, H, S-\mathrm{H}_{3} \mathrm{~B}(\mathrm{mp})\right\}(\mathrm{NBD})\right] .{ }^{5}$ In this previously reported complex, a much stronger ligand coordination was observed where the ${ }^{1} \mathrm{~J}_{\mathrm{RhH}}$ coupling constant was found to be $19.5 \mathrm{~Hz}$.

Scheme 3. Synthesis of $\left[\mathrm{Rh}\left\{\kappa^{3}-H, H, S-\mathrm{H}_{2} \mathrm{~B}(\mathrm{Ph})(\mathrm{mp})\right\}(\mathrm{NBD})\right]$ (1)

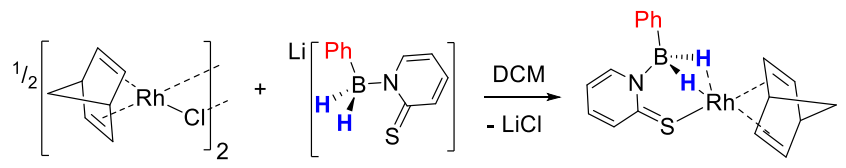

(1); $83 \%$

Single crystals of 1 were obtained by allowing a saturated diethyl ether solution stand at room temperature for $48 \mathrm{~h}$. The molecular structure, as determined by X-ray crystallography, is shown in Figure 1 . The structure is fully consistent with the spectroscopic data and supports the solution state assignment that the $\mathrm{BH}_{2}$ unit was bound to the rhodium center via a bridging $\mathrm{BH}_{2} \mathrm{Rh}$ mode. It also confirms the pseudo square planar geometry of the rhodium(I) metal center. The diene is coordinated to the rhodium center via a typical $\eta^{2}$ coordination mode. One of the double bonds is trans to the thione group whilst the other is trans to the anionic $\mathrm{BH}_{2}$ unit. The distances between the centroid of each $\mathrm{C}=\mathrm{C}$ bond and the rhodium center is 2.0379(14) $\AA$ for the double bond trans to thione donor and 1.9919(14) $\AA$ for the double bond trans to the $\mathrm{BH}_{2}$ unit. This indicates a weak trans influence of the anionic unit. ${ }^{5,9}$ The sum of the cis inter-angles for $\mathbf{1}$ is $360.03(14)^{\circ}$ when calculated using the sulfur and boron atoms along with the centroid positions of the alkene bonds of the norbornadiene ligand. The phenyl substituent at boron is oriented so that it is close to being perpendicular to the mercaptopyridine ring, as evidenced by a N1-B1-C6-C11 angle of $70.9(3)^{\circ}$. 


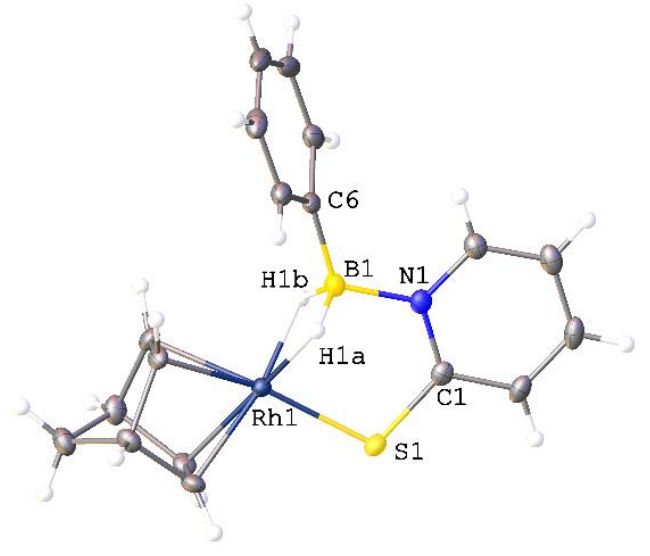

Figure 1. The molecular structure of complex 1. Thermal ellipsoids of all atoms with the exception of hydrogen are drawn at $50 \%$ level. Selected distances ( $\AA$ ) and angles $\left({ }^{\circ}\right) \mathrm{Rh}-\mathrm{B}$ 2.239(2), Rh-S 2.2981(5), B-N 1.567(3), B-C 1.590(3), Rh-H(1A) 1.84(2), RhH(1B) 1.83(2), B-H(1A) 1.20(2), B-H(1B) 1.21(2), C=S 1.729(2), $\mathrm{B}-\mathrm{Rh}-\mathrm{S}$ 83.68(6).

As highlighted in the introduction section, we were interested in further probing the reactivity of the borohydride unit with the coordinated norbornadiene ligand. Our previous results have shown that by disturbing the coordination sphere of the related complex $\left[\mathrm{Rh}\left\{\kappa^{3}-H, H, S-\mathrm{H}_{3} \mathrm{~B}(\mathrm{mp})\right\}(\mathrm{NBD})\right]$, the norbornadiene ligand undergoes a formal hydroboration. ${ }^{5}$ This leads to the formation of a secondary borohydride functional group (as indicated in Scheme 1). We aimed to explore similar conditions with the newly formed complex. Accordingly, solutions of complex 1 were subjected to various ligands. In our previous investigations, addition of carbon monoxide to [Rh $\left.\left\{\kappa^{3}-H, H, S-\mathrm{H}_{3} \mathrm{~B}(\mathrm{mp})\right\}(\mathrm{NBD})\right]$ led to the formation of $\left[\mathrm{Rh}\left\{\kappa^{3}-H, H, S-\mathrm{H}_{2} \mathrm{~B}(\mathrm{nbe})(\mathrm{mp})\right\}(\mathrm{CO})_{2}\right]$ as highlighted above. The same reaction was carried out with complex 1 in a Young's NMR tube using $\mathrm{C}_{6} \mathrm{D}_{6}$ solvent. Upon addition of an atmosphere of $\mathrm{CO}$, a color change from yellow to orange was observed. The ${ }^{11} \mathrm{~B}$ NMR spectrum of the reaction mixture after 20 min revealed partial conversion of the starting material to a new product (ca. 30\%). On the basis of the NMR spectroscopic characterization and the reactivity observed in similar complexes, we believe that the product formed in situ is of the formula, $\left[\mathrm{Rh}\left\{\kappa^{3}-H, H, S-\mathrm{H}_{2} \mathrm{~B}(\mathrm{Ph})(\mathrm{mp})\right\}(\mathrm{CO})_{\mathrm{n}}\right]_{\mathrm{x}}{ }^{10}$ This is the result of a ligand substitution reaction resulting in the elimination of the diene from the rhodium coordination sphere. Unfortunately, this reaction mixture showed signs of significant decomposition when left for longer periods and after $24 \mathrm{~h}$ almost all signs of any boron containing species were absent from the NMR solution. It was clear that the complex containing the $\left[\mathrm{H}_{2} \mathrm{~B}(\mathrm{Ph})(\mathrm{mp})\right]^{-}$ligand reacted differently to that containing the $\left[\mathrm{H}_{3} \mathrm{~B}(\mathrm{mp})\right]^{-}$ligand.

Complex 1 was next tested for its reactivity towards two equivalents of triphenylphosphine. A potential product of this again could have been straightforward ligand substitution of the norbornadiene ligand with the two monodentate phosphine ligands. In this case however, we observed an unusual transformation. Complex 1 was fully dissolved in $\mathrm{C}_{6} \mathrm{D}_{6}$ in the presence of two equivalents of $\mathrm{PPh}_{3}$ in a Young's NMR tube. Upon addition of the solvent, the mixture quickly changed colour from orange to red. The ${ }^{11} \mathrm{~B}$ NMR spectrum after 10 min showed the complete consumption of the starting material. The spectra contained a significantly broad signal centered at $34.7 \mathrm{ppm}$ (h.h.w. of $1550 \mathrm{~Hz}$ ) as the only resonance. This substantial change in the chemical shift and peak width was indicative of major change in the chemical environment of the boron center. The corresponding ${ }^{31} \mathrm{P}\left\{{ }^{1} \mathrm{H}\right\}$ NMR spectrum was also consistent with a single new product. The spectrum revealed two doublet of doublet signals indicating the coordination of two triphenylphosphine ligands cis to each other at the rhodium center. Accordingly, the reaction was carried out on a preparative scale (see Experimental Section). ${ }^{11}$ A pure brick-red solid, complex 2 , was isolated via a standard workup in very good yield and was fully characterized by spectroscopic and analytical methods. The two resonances in the ${ }^{31} \mathrm{P}\left\{{ }^{1} \mathrm{H}\right\}$ NMR spectrum were found at $31.9 \mathrm{ppm}$ $\left(\mathrm{dd},{ }^{1} \mathrm{~J}_{\mathrm{RhP}}=134 \mathrm{~Hz},{ }^{2} \mathbf{J}_{\mathrm{PP}}=33 \mathrm{~Hz}\right)$ and $47.8 \mathrm{ppm}\left(\mathrm{dd},{ }^{1} \mathrm{~J}_{\mathrm{RhP}}=176\right.$ $\mathrm{Hz},{ }^{2} \mathrm{~J}_{\mathrm{PP}}=33 \mathrm{~Hz}$ ). The coupling constant in the latter signal is consistent with a triphenylphosphine ligand trans to a sulfur based ligand. ${ }^{5}$ The smaller ${ }^{1} J_{\mathrm{RhP}}$ constant in the signal at $31.9 \mathrm{ppm}$ indicated that the other $\mathrm{PPh}_{3}$ ligand was trans to a ligand with a strong trans influence. The ${ }^{1} \mathrm{H}$ NMR spectrum was consistent with the coordination of two $\mathrm{PPh}_{3}$ ligands to the metal center (integrating for 30 $\mathrm{H})$. The spectrum also contains four new environments for a 2-mercaptopyridinyl unit and three environments for the phenyl group on boron. Comparisons of this spectrum and the corresponding ${ }^{1} \mathrm{H}\left\{{ }^{11} \mathrm{~B}\right\}$ NMR spectrum indicated that there were no hydrogen substituents at the boron center. Furthermore, there were no signals in the hydride regions of these spectra. It was therefore apparent that the two hydrogen substituents at boron in complex 1 had undergone a rather intriguing transformation during the reaction. Curiously, the signals corresponding to the NBD moiety, either as coordinated or uncoordinated diene in solution, were also absent. There were, however, two additional resonances at $5.58 \mathrm{ppm}$ and $5.67 \mathrm{ppm}$ each integrating for 1 proton and a number of new signals in the aliphatic region of the spectrum with a total integration of 8 protons. On the basis of this evidence, it was clear that the two former hydrogen substituents at boron had been incorporated into the norbornadiene $\left(\mathrm{C}_{7} \mathrm{H}_{8}\right)$ unit to provide a novel $\mathrm{C}_{7} \mathrm{H}_{10}$ organic fragment containing one double bond. The ${ }^{13} \mathrm{C}\left\{{ }^{1} \mathrm{H}\right\}$ NMR spectrum also confirmed the presence of a hydrocarbon fragment with seven carbon environments. $^{12}$

With this evidence we were confident that a transformation had occurred involving the former norbornadiene ligand and the two hydrogen atoms originally bound to the boron center. Single crystals of complex $\mathbf{2}$ were obtained by allowing a saturated acetone solution stand at room temperature for several days. These were of suitable quality for single crystal X-ray diffraction and allowed for the unambiguous structural determination of complex 2 (Scheme 4 and Figure 2). The crystal structure indeed confirmed that a remarkable and unprecedented transformation had occurred. The boron had lost both hydrogen substituents and a ring opening transformation had occurred on the former norbornadiene ligand to form an ethylene-yl bridged cyclopentene unit. Furthermore, this new organic unit resided at the boron centre and was coordinated to the rhodium centre via one of the carbons of the ethylene-yl bridge and the boron atom in a $\eta^{2}-B, C$ coordination mode. This rare functional group has only be observed in a handful of cases, ${ }^{13}$ although some similar borataalkenes motifs have been reported. ${ }^{14,15}$ The unique bonding features of the boron based ligand motif are outlined below.

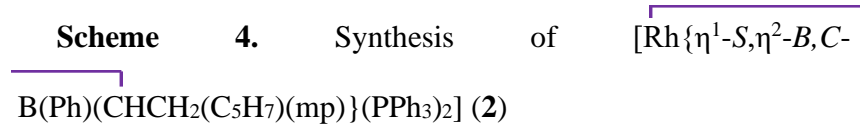

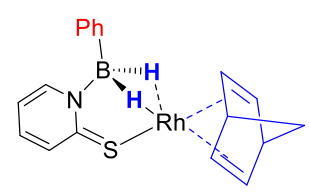

(1)

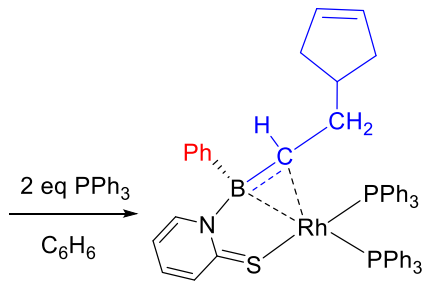

(2); $76 \%$ 
Close examination of the structure reveals a square planar rhodium(I) center where two triphenylphosphine ligands are cis to each other. The structure also reveals the coordination of the $\mathrm{B}(\mathrm{Ph})\left(\mathrm{CHCH}_{2}\left(\mathrm{C}_{5} \mathrm{H}_{7}\right)(\mathrm{mp})\right.$ ligand which binds to the rhodium centre via the thione and via both the $\alpha$-carbon and boron centres on the $\mathrm{BCHCH}_{2}\left(\mathrm{C}_{5} \mathrm{H}_{7}\right)$ group. The sulfur atom of the mercaptopyridine unit and the carbon atom $\alpha$ to the boron are located on the plane. The sum of the cis-inter ligand angles is $359.92(12)^{\circ}$ [ranging between $82.62(2)^{\circ}$ and $96.01(2)^{\circ}$ ]. The boron center is located at a distance $1.385(3) \AA$ below the plane defined by the atoms Rh1, C6, P1, P2 and S1. The C6- Rh(1)-B(1) angle is $37.79(8)^{\circ}$ and the $\mathrm{Rh}(1)-\mathrm{C}(6)$ and $\mathrm{Rh}(1)-\mathrm{B}(1)$ distances are 2.232(2) $\AA$ and 2.352(3) $\AA$, respectively. The $\mathrm{Rh}-\mathrm{B}$ distance is longer than previously reported for mercaptopyridine-borane based ligands. A survey of the Cambridge Structural Database revealed a range of compounds featuring a tricoordinate borane ligand which appears to be interacting with a rhodium center. In these cases, the $\mathrm{Rh}-\mathrm{B}$ distances ranged from $2.632 \AA^{16}$ to $2.053 \AA .{ }^{17}$ The positioning of the $\mathrm{C}(6)$ and $\mathrm{B}(1)$ atoms is of interest. The $\mathrm{Rh}(1)-\mathrm{C}(6)$ distance is typical of a $\sigma$-alkyl fragment coordinated trans to a triphenylphosphine ligand at a monovalent rhodium center. ${ }^{18}$ The corresponding $\mathrm{Rh}(1)-\mathrm{P}(2)$ distance is 2.3293(6) $\AA$ is consistent with a phosphine trans to an alkyl unit. The labilization or influence of the boron functionality at an angle of $140.30(7)^{\circ}$ for $\mathrm{B}(1)-\mathrm{Rh}(1)-\mathrm{P}(2)$ is not apparent or reflected in the $\mathrm{Rh}(1)-\mathrm{C}(6)$ distance. ${ }^{19}$ The $\mathrm{B}(1)-\mathrm{C}(6)$ distance is $1.489(3) \AA$. This is shorter than a typical boron carbon single bond [c.f. 1.584(3) $\AA$ as the $\mathrm{B}(1)-\mathrm{C}(13)$ distance in this same structure] and it is therefore suggestive of some multiple bond character within the rhodium bound $\eta^{2}-B, C$ unit. Furthermore, the angles around the boron center are, $\mathrm{N}(1)-\mathrm{B}(1)-\mathrm{C}(13) 112.35(18)^{\circ}, \mathrm{C}(6)$ $\mathrm{B}(1)-\mathrm{N}(1) 117.9(2)^{\circ}$ and $\mathrm{C}(6)-\mathrm{B}(1)-\mathrm{C}(13) 126.3(2)^{\circ}$. The sum of these three angles is $356.6(6)^{\circ}$ indicating a significant degree of planarity of the boron center. The above parameters appear to suggest that the boron is only weakly interacting with the rhodium center, most likely due to its position with respect to the square plane.

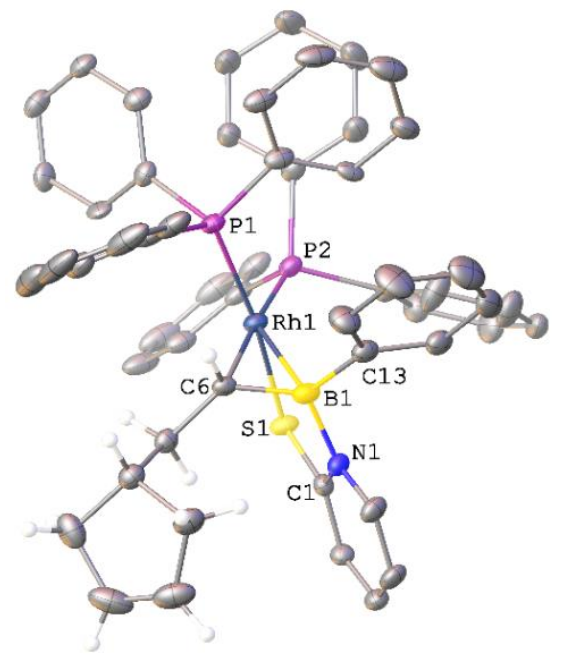

Figure 2. Molecular structure of Complex 2. Thermal ellipsoids drawn at 50\% level. Hydrogen atoms apart from those on the ethylenylcyclopentene have been omitted for clarity. Selected distances $(\AA)$ and angles $\left({ }^{\circ}\right) \mathrm{Rh}-\mathrm{B} 2.352(3), \mathrm{Rh}-\mathrm{S} 2.3449(6), \mathrm{Rh}-\mathrm{C}(6)$ 2.232(2), Rh-P(1) 2.2716(6), Rh-P(2) 2.3293(6) B-N 1.577(3), B$\mathrm{C}(13)$ 1.584(3), B-C(6) 1.489(3), $\mathrm{C}=\mathrm{S}$ 1.711(2), N-B-C(6) $117.9(2), \mathrm{N}-\mathrm{B}-\mathrm{C}(13)$ 112.35(18), C(6)-B-C(13) 126.3(2), B-Rh$\mathrm{S}$ 79.95(6), B-Rh-P(1) 105.67(6), C(6)-Rh-S 91.86(6), C(6)-Rh$\mathrm{P}(1)$ 89.43(6), S-Rh-P(2) 82.62(2), P(1)-Rh-P(2) 96.01(2), $\sum$ of angles at $\mathrm{Rh} 359.92(12)$.
The reactivity of complex 2 with carbon monoxide was investigated. This led to the formation of $\left[\operatorname{Rh}\left\{\eta^{1}-S, \eta^{2}-B, C-\right.\right.$ $\left.\mathrm{B}(\mathrm{Ph})\left(\mathrm{CHCH}_{2}\left(\mathrm{C}_{5} \mathrm{H}_{7}\right)(\mathrm{mp})\right\}(\mathrm{CO})\left(\mathrm{PPh}_{3}\right)\right]$ (3). Complex 3 was prepared via a straightforward ligand substitution step involving the addition of carbon monoxide to a solution of complex 2 (Scheme 5). Alternatively, complex 3 could be also be prepared in a "onepot" procedure directly from complex 1 . Both methods provided the product as a spectroscopically pure solid in good yield. The spectroscopic data for $\mathbf{3}$ were comparable to those for complex $\mathbf{2}$. A minor difference was related to the chemical equivalence of alkene and adjacent methylene groups within the cyclopentenyl ring. This is presumably due to the reduction of steric bulk upon going from two triphenylphosphine ligands to one, which facilitates unhindered rotation of this unit within the complex. The ${ }^{1} \mathrm{~J}_{\mathrm{RhP}}$ coupling constant $(133 \mathrm{~Hz})$ observed in the ${ }^{31} \mathrm{P}\left\{{ }^{1} \mathrm{H}\right\}$ NMR spectrum confirmed that the remaining phosphine ligand was located trans to the $B C$ unit (essentially trans to the carbon atom). Confirmation for the coordination of a carbonyl to the rhodium center came from the ${ }^{13} \mathrm{C}\left\{{ }^{1} \mathrm{H}\right\}$ NMR spectrum with a doublet of doublet signal at 193.3 ppm with ${ }^{1} \mathbf{J}_{\mathrm{RhC}}$ and ${ }^{2} \mathbf{J}_{\mathrm{CP}}$ coupling constants $72 \mathrm{~Hz}$ and $15 \mathrm{~Hz}$, respectively. This is further evidenced in the powder IR spectrum of 3 which gave a very strong absorption band at $1945 \mathrm{~cm}^{-1}$ characteristic of a coordinated carbonyl stretching.

$\begin{array}{llll}\text { Scheme } & \text { 5. Synthesis of } & {\left[\mathrm{Rh}\left\{\eta^{1}-S, \eta^{2}-B, C-\right.\right.} \\ \left.\mathrm{B}(\mathrm{Ph})\left(\mathrm{CHCH}_{2}\left(\mathrm{C}_{5} \mathrm{H}_{7}\right)(\mathrm{mp})\right\}(\mathrm{CO})\left(\mathrm{PPh}_{3}\right)\right](3) . & \end{array}$

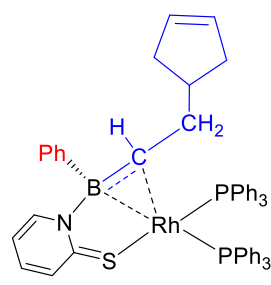

(2)

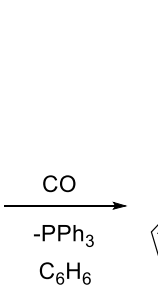

$\mathrm{C}_{6} \mathrm{H}_{6}$

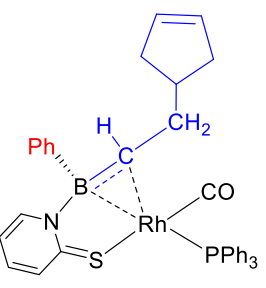

(3); $61 \%$
Complex 3 was also structurally characterized. Single crystals suitable for X-ray crystallography where obtained by allowing a saturated diethyl ether solution of the complex stand at $-40{ }^{\circ} \mathrm{C}$ for several days (Figure 3 ). The structure obtained confirmed the coordination of the $\mathrm{PPh}_{3}$ and $\mathrm{CO}$ ligands coordinated cis to each other at the rhodium center and that the $\mathrm{CO}$ is trans to the thione unit while the phosphine is trans to the $B C$ unit. As with complex $\mathbf{2}$, the carbon center of the $B C$ unit is positioned close to one of the idealized position of a square planar complex. The sum of the cis-inter ligand angles is $360.7(2)^{\circ}$ [ranging between $81.39(7)^{\circ}$ and $\left.100.42(5)^{\circ}\right]$. The boron center was located at a distance 1.063(3) $\AA$ below the plane defined by the atoms Rh1, C6, P1, C19 and S1. The C6- $\mathrm{Rh}(1)-\mathrm{B}(1)$ angle is $36.89(7)^{\circ}$ and the $\mathrm{Rh}(1)-\mathrm{C}(6)$ and $\mathrm{Rh}(1)-\mathrm{B}(1)$ distances are 2.2728(18) $\AA$ and 2.369(2) $\AA$, respectively. The corresponding $\mathrm{Rh}(1)-\mathrm{P}(1)$ distance is $2.2993(4)$. The $\mathrm{B}(1)-\mathrm{C}(6)$ distance is $1.471(3) \AA$. The angles around the boron center are $\mathrm{N}(1)-\mathrm{B}(1)-\mathrm{C}(6) \quad 114.78(17)^{\circ}, \quad \mathrm{C}(13)-\mathrm{B}(1)-\mathrm{N}(1)$ $113.61(16)^{\circ}$ and $\mathrm{C}(13)-\mathrm{B}(1)-\mathrm{C}(6) 129.17(17)^{\circ}$. The sum of these three angles is $357.5(5)^{\circ}$. All of these parameters are similar to those found for complex 2 .

\section{Transformation of Complex 1 to Complexes 2 and 3}

The ring strain within norbornadiene means that it readily undergoes transformations at transition metal centers such as ring opening polymerizations, other types of ring opening and additions across the double bonds. In particular, addition of dihydrogen 
across the double bonds in norbornadiene is well established. To the best of our knowledge, the transformation of a norbornadiene unit to form an ethylene-yl bridged cyclopentene unit is without precedent. The mechanism of this transformation was not immediately obvious given the position of the double bond in the final product. It was clear that both hydrogen substituents at boron had been incorporated into the former norbornadiene unit. The way in which the bicyclic ring opened was not clear, at first. In order to gain a more detailed insight we carried out a number of deuterium labelling studies to work out the endpoint positions of the hydrogen substituents originating from the boron center. The method utilized to determine the endpoint positions of these two hydrogen is presented below and has led us to postulate a mechanism for the transformation (vide infra).

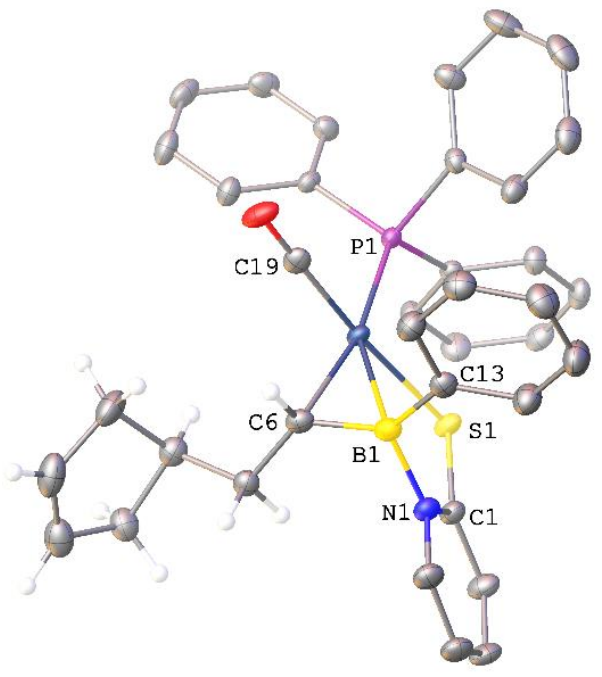

Figure 3. Molecular structure of complex 3. Thermal ellipsoids drawn at 50\% level. Hydrogen atoms apart from those on the ethylenylcyclopentene have been omitted for clarity. Selected distances $(\AA)$ and angles $\left(^{\circ}\right) \mathrm{Rh}-\mathrm{B} 2.369(2), \mathrm{Rh}-\mathrm{S} 2.3446(4), \mathrm{Rh}-\mathrm{C}(6)$ 2.2728(18), Rh-C(19) 1.8345(19), Rh-P(1) 2.2993(4), B-N 1.570(2), B-C(6) 1.471(3), B-C(13) 1.576(3), C=S 1.7260(18), N$\mathrm{B}-\mathrm{C}(6) \quad 114.78(17), \quad \mathrm{N}-\mathrm{B}-\mathrm{C}(13) \quad 113.61(16), \quad \mathrm{C}(6)-\mathrm{B}-\mathrm{C}(13)$ 129.17(17), B-Rh-S 78.46(5), B-Rh-C(19) 100.53(7), C(6)-RhS 100.42(5), C(6)-Rh-C(19) 81.39(7), S-Rh-P(1) 88.622(16), $\mathrm{C}(19)-\mathrm{Rh}-\mathrm{P}(1)$ 90.27(6), $\sum$ of angles at Rh 360.7(2).

Firstly, the deuterium labelled ligand, $\operatorname{Li}\left[\mathrm{D}_{2} \mathrm{~B}(\mathrm{Ph})(\mathrm{mp})\right]$ was prepared by the same methodology used for the preparation of $\mathrm{Li}\left[\mathrm{H}_{2} \mathrm{~B}(\mathrm{Ph})(\mathrm{mp})\right]$ (see Experimental Section). The corresponding labelled complex, $\left[\mathrm{Rh}\left\{\kappa^{3}-D, D, S-\mathrm{D}_{2} \mathrm{~B}(\mathrm{Ph})(\mathrm{mp})\right\}(\mathrm{NBD})\right] \mathbf{1 - d _ { 2 }}$ was subsequently prepared by the same method used for 1 . The spectroscopic data for this labelled complex was as expected and were comparable to those for $\mathbf{1}$. The pertinent features are outlined herein. Whereas the $\mathrm{BH}_{2}$ unit appeared as a triplet in the ${ }^{11} \mathrm{~B}$ NMR spectrum for $\mathbf{1}$, an unresolved broader signal was observed for 1-d2 where the ${ }^{1} \mathrm{~J}_{\mathrm{BD}}$ coupling was not observable. As indicated above, the $\mathrm{BH}_{2}$ unit was observed as a doublet signal at $-1.59 \mathrm{ppm}$ in the ${ }^{1} \mathrm{H}\left\{{ }^{11} \mathrm{~B}\right\}$ NMR of 1 . The corresponding $\mathrm{BD}_{2}$ unit was located at $-1.58 \mathrm{ppm}$ in the ${ }^{2} \mathrm{D}$ NMR spectrum of 1-d2. With this deuterium labelled complex in hand, we subjected it to the same reaction conditions used in the synthesis of $\mathbf{2}$, i.e. two equivalents of triphenylphosphine were added to a benzene solution of 1-d2. The resulting product was carefully analyzed by NMR spectroscopy in order to confirm the product and the final location of the two deuterium atoms. No deuterium scrambling was apparent over time. The chemical shifts of all carbon and proton environments within the ethylene-yl bridged cyclopentene unit were determined by two dimensional correlation experiments. Interestingly and fortuitously, there appeared to be no rotation of the organic moiety. This aided our assignment and helped build a picture of the mechanism for this transformation. When samples were heated up to $80{ }^{\circ} \mathrm{C}$, they showed no indication of rotation of the cyclopentenyl ring. ${ }^{20}$

Complex 2-d2 was confirmed as $\left[\operatorname{Rh}\left\{\eta^{1}-S, \eta^{2}-B, C\right.\right.$ -

$\left.\mathrm{B}(\mathrm{Ph})\left(\mathrm{CHC}(\mathrm{H}) \mathrm{D}\left(\mathrm{C}_{5} \mathrm{H}_{6} \mathrm{D}\right)(\mathrm{mp})\right\}\left(\mathrm{PPh}_{3}\right)_{2}\right]$ where one deuterium atom was located at the carbon $\beta$ to the boron and the other at one of the allylic positions within the cyclopentene ring (as shown in Scheme 6). The deuterium was located on only one side of the cyclopentene ring which confirms no rotation of the cyclopentenyl ring in solution. This also suggests that the conformation observed in the crystal structure for this compound is the same as that found in solution.

Locating the endpoint positions of the two deuterium atoms was relatively straightforward. A comparison of the aliphatic region of the ${ }^{1} \mathrm{H}$ NMR spectra of complexes $\mathbf{2}$ and $\mathbf{2 - \mathbf { d } _ { 2 }}$ is shown in Figure 4. As can be seen, there are two signals which are absent in the spectrum for $\mathbf{2 - d}$. The signal at $2.84 \mathrm{ppm}$ in the spectrum of $\mathbf{2}$ is missing in the spectrum for $\mathbf{2 - d}$. This corresponds to one of the two methylene protons on the carbon $\beta$ to the boron atom. The second missing signal is a multiplet signal centered at $2.03 \mathrm{ppm}$. In the spectrum of $\mathbf{2}$, this consists of 2 overlapping signals integrating for 2 protons. In $\mathbf{2}-\mathbf{d}_{\mathbf{2}}$ this only integrates for 1 proton. As a result of the lack of rotation, all four of the methylene signals were found at different chemical shifts. Two overlapping signals at $2.04 \mathrm{ppm}$ were confirmed as the proton attached to carbon $\gamma$ to the boron and one of the four methylene protons within the cyclopentenyl ring. We were able to confirm that the signal that remained at this chemical shift in 2-d2 corresponded to a $\mathrm{CH}$ unit (as opposed to a $\mathrm{CH}_{2}$ unit) via a HSQC experiment (see Figures S11.1 and S11.2 in the supporting information). This was identified as the $\mathrm{CH}$ in the position $\gamma$ to the boron center. As such, we confirmed that the deuterium substituents were attached to carbon- 2 and carbon- 7 as indicted in the numbering scheme for the organic unit in Scheme 6. Further support for our assignments was obtained from the corresponding

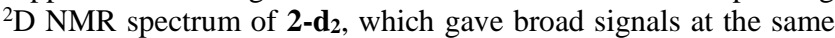
chemical shifts as the missing signals in the ${ }^{1} \mathrm{H}$ NMR spectrum of 2. In an attempt to ascertain the stereochemistry of deuterium in-

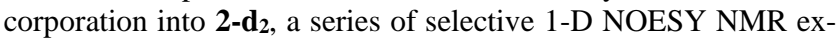
periments where performed (details of these experiments can be found in the Electronic Supporting Information). These, in combination with analysis of the COSY NMR experiment of $\mathbf{2}$, allowed the confirmation of the exact locations of the deuterium atoms. Both deuterium atoms added to the endo face of the former norbornadiene ligand in the positions indicated in Scheme 6 .

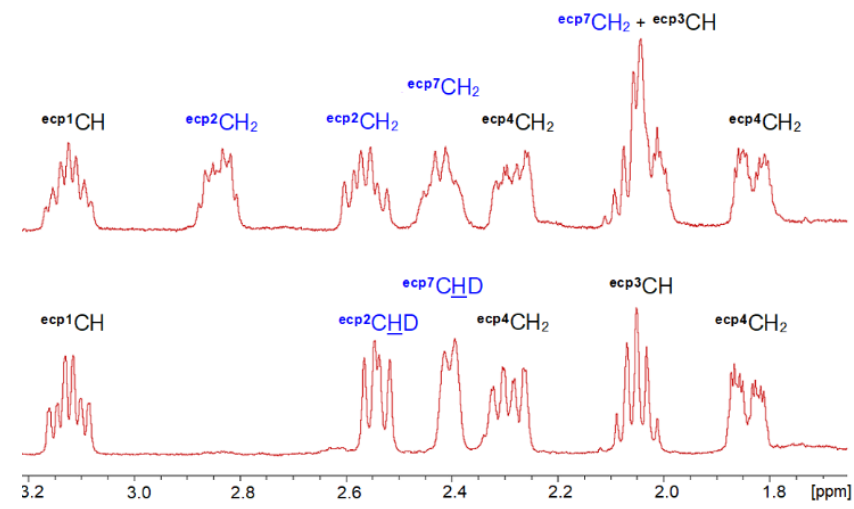

Figure 4. Comparison of the aliphatic region of the ${ }^{1} \mathrm{H}$ NMR spectra for complexes $\mathbf{2}$ (top) and $\mathbf{2}-\mathbf{d}_{2}$ (bottom) indicating the positions of the deuterium atoms by their absence in the spectrum for 2-d2 (see Scheme 6 for numbering scheme). 
Scheme 6. Postulated mechanism for synthesis of $\left[\mathrm{Rh}\left\{\eta^{1}-S, \eta^{2}-B, C-\mathrm{B}(\mathrm{Ph})\left(\mathrm{CHCH}(\mathrm{D})\left(\mathrm{C}_{5} \mathrm{H}_{6} \mathrm{D}\right)(\mathrm{mp})\right\}\left(\mathrm{PPh}_{3}\right)_{2}\right]\left(\mathbf{2}^{\left.-\mathbf{d}_{2}\right)}\right.\right.$

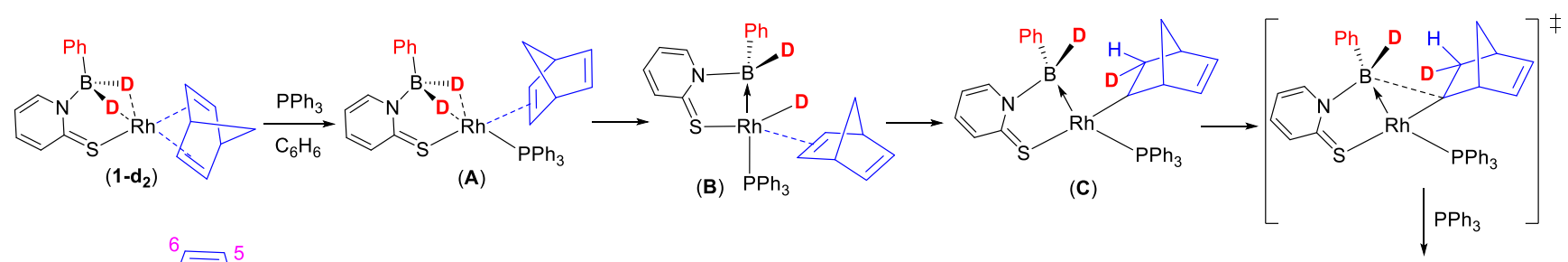

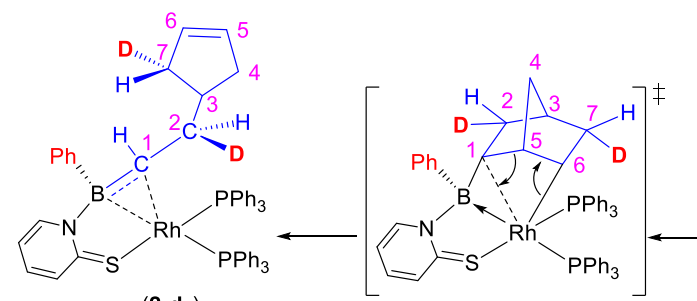

$\left(2-d_{2}\right)$

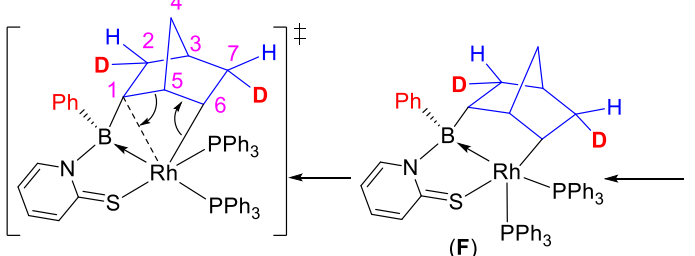

(F)

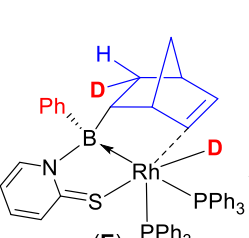

(E) $\mathrm{PPh}_{3}$

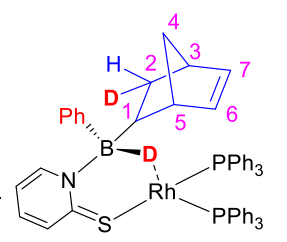

(D)
With conformation of the positions of the deuterium atoms within 2-d2, it was possible to work out a consistent mechanism for this transformation (Scheme 6). Our rationale for this mechanism is outlined herein. A number of studies have been carried out looking at the hydrogenation of the norbornadiene ligand at late transition metal centers. ${ }^{21}$ In several cases, the norbornadiene undergoes migration into a transition metal-hydride species to form norbornenyl or its valence isomer, nortricyclyl unit. ${ }^{21,22}$ The formation of a nortricyclyl unit was ruled out in this case since there is no $\mathrm{C}-\mathrm{C}$ bond breaking route which would lead to a product containing a five membered ring. Next, we considered a fully intermolecular route. In order to rule this out we investigated the reactivity of the complex $\left[\mathrm{Rh}\left\{\kappa^{3}-H, H, S-\mathrm{H}_{2} \mathrm{~B}(\mathrm{Ph})(\mathrm{mp})\right\}\left(\mathrm{PPh}_{3}\right)_{2}\right](\mathbf{4})^{23}$ with free norbornadiene (Scheme 7). If an intermolecular transformation was occurring in the formation of complex $\mathbf{2}$, then complex $\mathbf{4}$ would be an intermediate. The norbornadiene species would undergo consecutive, or perhaps concerted, additions across both double bonds. This would be a hydroboration at the boron center and a migratory insertion into a newly formed rhodium-hydride species. Prior to both these transformations occurring, a hydride migration from the borohydride species to the rhodium center would need to occur (since a tricoordinate boron is a pre-requisite for hydroboration). We can confirm that there was no evidence of any reactivity between complex $\mathbf{4}$ and free norbornadiene over several days.

Scheme 7. Attempted reaction to rule out an intermolecular mechanism to form complex 2

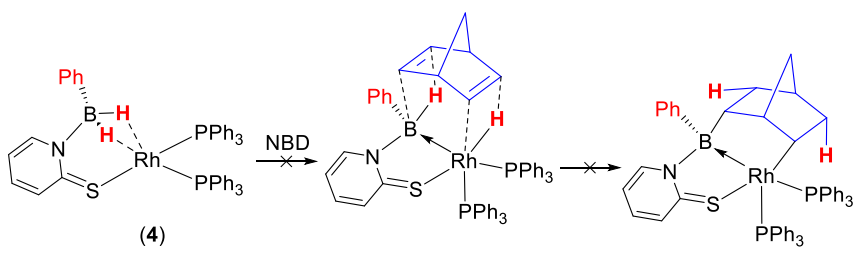

The fact that complete conversion of $\mathbf{1}$ into $\mathbf{2}$ occurs within 10 min suggests a series of rapid intramolecular reaction steps as outlined in Scheme 6. We do have precedent for the earlier steps leading to species D. As highlighted above, our previous results from the related complex, $\left[\mathrm{Rh}\left\{\kappa^{3}-H, H, S-\mathrm{H}_{3} \mathrm{~B}(\mathrm{mp})\right\}(\mathrm{NBD})\right]$ leads to the formation of $\left[\mathrm{Rh}\left\{\kappa^{3}-H, H, S-\mathrm{H}_{2} \mathrm{~B}(\mathrm{nbe})(\mathrm{mp})\right\}(\mathrm{L})_{2}\right]$ (where $\mathrm{L} / \mathrm{L}=$ $\mathrm{CO} / \mathrm{CO}$ or $\left.\mathrm{CO} / \mathrm{PPh}_{3}\right)$ following a similar ligand substitution based activation (Scheme 1). ${ }^{5}$ On the basis of these observations, and the number of examples involving hydride migration from borohydride species, ${ }^{2,3}$ we believe that the steps leading up to the formation of
$\left[\mathrm{Rh}\left\{\kappa^{2}-H, S-\mathrm{H}_{2} \mathrm{~B}(\mathrm{Ph})(\mathrm{nbe})(\mathrm{mp})\right\}\left(\mathrm{PPh}_{3}\right)_{2}\right]$, labelled species $\mathbf{D}$ in Scheme 6 , are analogous. It is therefore likely that the transformation from 1 entails a change in the coordination mode of the norbornadiene ligand from $\eta^{4}$ to $\eta^{2}$, induced by coordination of the first phosphine ligand (1-d $\mathbf{1}$ to $\mathbf{A})$. This is followed by a migration of hydride (or deuteride in the case of 1-d2) from the borohydride to the rhodium center (A to $\mathbf{B}$ ). The next step is a migratory insertion step of the diene into the rhodium-hydride leading to the formation of the norbornenyl (nbe) unit (B to $\mathbf{C}$ ) which migrates to the borane group to form species $\mathbf{D}$. The location of the deuterium atom in 2$\mathbf{d}_{2}$ confirms syn-addition of the rhodium deuteride across the double bond.

For our previously reported system, containing the parent $\mathrm{BH}_{3}$ ligand, it appears that the transformation stops at this point and the stable complexes of the type $\left[\mathrm{Rh}\left\{\kappa^{3}-H, H, S-\mathrm{H}_{2} \mathrm{~B}(\mathrm{nbe})(\mathrm{mp})\right\}(\mathrm{L})_{2}\right]$ remains as the final product. For the phenyl substituted ligand reported herein, the transformation appears to proceed further. There are a number of differences between species $\mathbf{D}$ and those complexes $\left[\mathrm{Rh}\left\{\kappa^{3}-H, H, S-\mathrm{H}_{2} \mathrm{~B}(\mathrm{nbe})(\mathrm{mp})\right\}(\mathrm{L})_{2}\right]$. Firstly, as a consequence of the substitution at boron, the coordination mode of the ligand is $\kappa^{2}-H, S$ in $\mathbf{D}$ whereas in the previously reported complexes the coordination mode is $\kappa^{3}-H, H, S$. Clearly, the $\mathrm{B}-\mathrm{H}---\mathrm{Rh}$ interaction in $\mathbf{D}$ would not be expected to be as strong as the $\mathrm{BH}_{2} \mathrm{Rh}$ dihydroborate interactions $\left(\kappa^{1}-H v s \kappa^{2}-H, H\right) .{ }^{8,9,24}$ Thus, it is likely to be more reactive. The change in steric bulk and the electron density at boron might also be responsible for further reactivity. Finally, at least one of the co-ligands in the previously reported complexes is a CO ligand. In species $\mathbf{D}$ both co-ligands are triphenylphosphine. This might also have a bearing on whether subsequent transformations occur. ${ }^{25}$

The conversion of $\mathbf{1}$ to $\mathbf{2}$ was complete within $15 \mathrm{~min}$ and it was not possible to observe any intermediate species spectroscopically. The postulated mechanism is based on the location of the deuterium atoms within $\mathbf{2}-\mathbf{d} \mathbf{2}$. The location of the deuterium atom at the position labelled 2 in Scheme 6 is consistent with the aforementioned steps leading to the formation of intermediate species $\mathbf{D}$. This is consistent with a straightforward addition across the double bond (positions 1 and 2). The subsequent steps are a little less clear since the double bond in the product $\mathbf{2}\left(\mathbf{2}-\mathbf{d}_{2}\right)$ is in a different position than in species $\mathbf{D}$ (c.f. positions 5 and 6 in the product $\mathbf{2}$ (or 2-d2) versus 6 and 7 in D). Furthermore, the $\mathrm{C}-\mathrm{C}$ bond between positions 1 and 5 is broken in the product. With the norbornenyl group attached to the boron center, the double bond in this organic unit can be held in a specific conformation in close proximity to the rhodium center for further reactivity (as demonstrated in Scheme 6). For this to occur, the remaining hydrogen (or deuterium) from boron must be transferred to the rhodium center ( $\mathbf{D}$ to $\mathbf{E})$. A migratory insertion 
of the double bond would occur leading to species $\mathbf{F}$, the product that would be formed as a result of a formal hydroboration on one double bond of norbornadiene and a migration insertion into the other double bond. This would lead to the addition of the deuterium atom on the endo face which is consistent with our assignment of the location of the deuterium atoms. In this sense, the rhodium and boron centers are working "in cooperation" to perform these transformations. The final step, $\mathbf{F}$ to $\mathbf{2}$ (or $\mathbf{2}-\mathbf{d}_{2}$ ), involves an unprecedented concerted ring opening step where the newly formed $\mathrm{Rh}-\mathrm{C}$ bond is broken, a double bond between the carbons 5 and 6 is formed and a rhodium-carbon bond is formed with carbon 1 . In summary, these steps involve a concerted ring opening process on the norbornenyl unit between the rhodium and boron centres.

\section{Cleavage of the $\mathrm{H}-\mathrm{H}$ Bond Across the $\boldsymbol{\eta}^{\mathbf{2}}-\boldsymbol{B}, \boldsymbol{C}$ Unit}

As outlined above, there are limited examples of $\eta^{2}-B, C$ coordination modes or related compounds reported within the chemical literature. ${ }^{12-14}$ This unit has been incorporated into palladium catalysts with applications for trans hydroboration of 1,3-enynes. ${ }^{12} \mathrm{~A}$ recent computational study by Shi focusing on the involvement of the $\eta^{2}-B, C$ unit within the mechanism of hydroboration confirmed that it plays an instrumental role within the catalytic reaction. ${ }^{120}$ This role is related to its tight interaction with the metal center and steric impact rather than any specific transformations involving this functional group, however. Their calculations ruled out any ligandassisted activation of the borane substrate within the catalytic reaction. Thus, a borohydride intermediate was not involved in the transformation within these hydroborations. This evidence suggested that it might not be possible to carry any further transformation on the $\eta^{2}-B, C$ unit within complexes 2 and 3 . On the other hand, there has been a number of examples in which ligand-assisted activations have indeed occurred across Z-type transition metal borane complexes. ${ }^{2}$ The rhodium-borane distances in complexes 2 and 3 are 2.352(3) $\AA$ and 2.367(2) $\AA$, respectively. These distances appear to suggest that it might be possible for the boron center to accommodate a hydride species without significant rearrangement (c.f. the Rh---B distance of 2.240(2) $\AA$ in complex 1 which features a $\mathrm{BH}_{2} \mathrm{Rh}$ bridging unit). We therefore set out to explore the reactivity of $\mathbf{2}$ and $\mathbf{3}$ with $\mathrm{H}_{2}$ since this could open up a new strategy for the activation of element-element bonds. ${ }^{2,26}$

Solutions of 2 and $\mathbf{3}$ in $\mathrm{C}_{6} \mathrm{D}_{6}$ were placed under a hydrogen atmosphere in a Young's NMR tubes and investigated by NMR spectroscopy. An immediate change in color was evident in the reaction involving 2 where the mixture became lighter in color. The ${ }^{11} \mathrm{~B}$ NMR spectrum confirmed the complete conversion to a new compound, complex $\mathbf{5}$, within $10 \mathrm{~min}$ (Scheme 8). The very broad resonance at $34.7 \mathrm{ppm}$ for the starting material was replaced by a singlet at 5.6 ppm (h.h.w. $=700 \mathrm{~Hz}$ ). This large upfield change in chemical shift is indicative of the formation of a tetra-coordinated borate species. The corresponding ${ }^{11} \mathrm{~B}\left\{{ }^{1} \mathrm{H}\right\}$ NMR spectrum did not provide any clear indication of the formation of a $\mathrm{B}-\mathrm{H}$ bond in this case because the signal was too broad to distinguish between the coupled and decoupled spectra. On the other hand, the corresponding ${ }^{1} \mathrm{H}$ and ${ }^{1} \mathrm{H}\left\{{ }^{11} \mathrm{~B}\right\}$ NMR spectra gave clear evidence for the addition of a hydrogen substituent at the boron center. A well resolved doublet of doublet of doublets signal was located in the hydride region of the spectrum at $-6.88 \mathrm{ppm}\left({ }^{1} \mathrm{~J}_{\mathrm{RhH}}=46 \mathrm{~Hz},{ }^{2} \mathrm{~J}_{\mathrm{PHtrans}}=20\right.$ $\mathrm{Hz}$ and ${ }^{2} \mathrm{~J}_{\mathrm{PHcis}}=9 \mathrm{~Hz}$ ). This signal was broad in the corresponding ${ }^{1} \mathrm{H}$ NMR spectrum which indicates that this hydrogen is located at the quadrupolar boron center. The chemical shift is also typical for a single $\mathrm{B}-\mathrm{H}$ unit interacting with the rhodium metal center. The coupling pattern for the $\mathrm{BH}$ signal confirms that the two $\mathrm{PPh}_{3}$ ligands remain coordinated to the metal center $c i s$ to each other. This is also supported by the presence of two doublet of doublet signals in the ${ }^{31} \mathrm{P}\left\{{ }^{1} \mathrm{H}\right\}$ NMR spectrum. The first is centered at $38.6 \mathrm{ppm}$ $\left({ }^{1} \mathrm{~J}_{\mathrm{RhP}}=168 \mathrm{~Hz},{ }^{2} \mathrm{~J}_{\mathrm{PP}}=45 \mathrm{~Hz}\right)$, which corresponds to the $\mathrm{PPh}_{3}$ ligand trans to the $\mathrm{BH}$ unit, and a second at $45.5 \mathrm{ppm}\left({ }^{1} \mathrm{~J}_{\mathrm{RhP}}=183 \mathrm{~Hz}\right.$ and ${ }^{2} \mathrm{JPP}_{\mathrm{PP}}=45 \mathrm{~Hz}$ ), which corresponds to the $\mathrm{PPh}_{3}$ ligand trans to the thione unit. With one hydrogen located at the boron center, it was necessary to work out the location of the second hydrogen atom. Eleven protons were identified in the ${ }^{1} \mathrm{H}$ NMR spectrum for the ethylenyl-1-cyclopentenyl group confirming that an additional hydrogen had indeed been incorporated into this fragment. It was, however, difficult to identify its specific location since these signals corresponded to a large number of multiplets in the spectrum. In order to confirm the location, a further deuterium labelling experiment was performed to make the analogous complex 5-d $\mathbf{2}$, via addition of $\mathrm{D}_{2}$ to complex $\mathbf{2}$. A comparison of the spectra for $\mathbf{5}$ and 5-d2 revealed that the $\mathrm{H}_{2}$ (or $\mathrm{D}_{2}$ ) had been added to the boron center (as discussed above) and to a methylene group adjacent to the boron (signal at $0.56 \mathrm{ppm}$ ). These assignments were confirmed by ${ }^{13} \mathrm{C}\left\{{ }^{1} \mathrm{H}\right\}$ NMR spectroscopy and a series of correlation experiments. These results indeed confirm the activation of $\mathrm{H}_{2}$ via formal addition across the $\eta^{2}-B, C$ bond. To the best of our knowledge this is an unprecedented transformation. Removal of the hydrogen atmosphere led to decomposition of the complex, unfortunately. Furthermore, leaving a diethyl ether solution of $\mathbf{5}$ under a hydrogen atmosphere for several days led to the isolation of single crystals identified as $\left[\mathrm{RhH}_{2}\left(\kappa^{2}-S, N-\mathrm{mp}\right)\left(\mathrm{PPh}_{3}\right)_{2}\right]$ (complex 7; see supporting information for details). ${ }^{27}$

Scheme 8. Reactivity of $\mathbf{2}$ and $\mathbf{3}$ with $\mathrm{H}_{2}$.

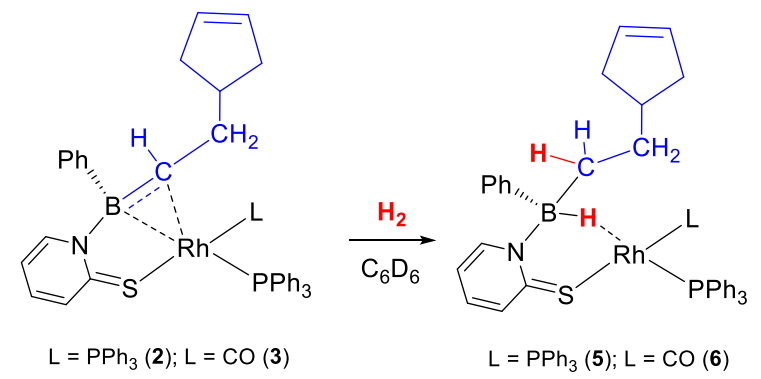

Addition of $\mathrm{H}_{2}$ to a $\mathrm{C}_{6} \mathrm{D}_{6}$ solution of complex 3 exhibited the same reactivity. In this case the reactivity was significantly slower and it took $6 \mathrm{~d}$ for the reaction to go to completion. Nevertheless,
the
analogous
complex,
$\left[\mathrm{Rh}\left\{\kappa^{2}-H, S-\right.\right.$

$\left.\left.\mathrm{HB}(\mathrm{Ph})\left(\mathrm{CH}_{2} \mathrm{CH}_{2} \mathrm{C}_{5} \mathrm{H}_{7}\right)(\mathrm{mp})\right\}(\mathrm{CO})\left(\mathrm{PPh}_{3}\right)\right]$ (6) was characterized via NMR spectroscopy (see Experimental Section). This compound also degraded slowly in solution when left for periods of over a week. As with 5, it was not possible to isolate a solid sample of $\mathbf{6}$ since it decomposed in the absence of a hydrogen atmosphere.

Both complexes $\mathbf{5}$ and $\mathbf{6}$ could also be synthesized by utilizing dimethylamine borane as source of hydrogen. ${ }^{28}$ In a typical reaction, ten equivalents of the amine borane were added to a $\mathrm{C}_{6} \mathrm{D}_{6}$ solution of complexes $\mathbf{2}$ or $\mathbf{3}$, respectively. The complete conversion of 2 to 5 occurred within $1 \mathrm{~h}$ at room temperature where the main boron containing by-products were identified as $\mathrm{H}_{2} \mathrm{~B}=\mathrm{NMe}_{2}$ and $\mathrm{NMe}_{2} \mathrm{~B}(\mathrm{H}) \mathrm{NMe}_{2}{ }^{28,29}$ Dehydrogenation of the remaining equivalents of amine-borane occurred when left for $24 \mathrm{~h}$ resulting in the formation the cyclic dimer product, $\left[\mathrm{H}_{2} \mathrm{BNMe}_{2}\right]_{2}$.

\section{Hydrogen Based Catalysis}

We and others have previously demonstrated the catalytic activation of hydrogen involving boron based ligands. ${ }^{26}$ Given the reactivity of complexes $\mathbf{2}$ and $\mathbf{3}$ with molecular hydrogen (either by 
direct addition or utilizing dimethylamine borane as a $\mathrm{H}_{2}$ source) and its formal addition across the $\eta^{2}-B, C$ unit, it prompted us to explore their potential role as catalysts in hydrogenation and dehydrogenation transformations. Both complexes $\mathbf{2}$ and $\mathbf{3}$ were found to be active catalysts for the dehydrogenation of dimethylamine borane. Reactions were attempted with $5 \mathrm{~mol} \%$ catalytic loading of either $\mathbf{2}$ or $\mathbf{3}$ in benzene as solvent. Conversions were recorded after 20 h. For complex 2 , a $95 \%$ conversion was recorded whilst a conversion of $<5 \%$ was recorded for 3 . Whilst these results demonstrate promise, there are other systems within the chemical literature which show greater catalytic activity for such dehydrogenation reactions. ${ }^{28}$

Complexes $\mathbf{2}$ and $\mathbf{3}$ were also tested for their application as hydrogenation catalysts. The results of these are highlighted in Table 1. Preliminary investigations reveal that these complexes are active catalysts for the hydrogenation of the substrates styrene and cyclooctene utilizing both $\mathrm{H}_{2}$ gas or dimethylamine borane $(\mathrm{AB})$ as sources of hydrogen. Direct use of $\mathrm{H}_{2}$ gas was most efficient in almost all cases, as expected. The two substrates were fully converted to ethyl benzene and cyclooctane, respectively at 2.0 bar $\mathrm{H}_{2}$ at 80 ${ }^{\circ} \mathrm{C}$ over a period of $18 \mathrm{~h}$, utilizing $5 \mathrm{~mol} \%$ catalytic loading of complex 2. Under all conditions tested, complex 2 demonstrated higher activities than complex $\mathbf{3}$. This is likely due to the ligand dissociation step required for the alkene substrate to coordinate to the metal center. Ligand dissociation is mostly likely to be more favorable in the bis-triphenylphosphine complex. At lower catalyst loadings (1.0 $\mathrm{mol} \%$ and $0.1 \mathrm{~mol} \%$ ), these substrates were reduced to their corresponding alkanes with lower conversions. Further investigations and optimizations are currently being carried out to explore the role of the $\eta^{2}-B, C$ unit within the catalytic cycle of these hydrogenations.

\section{Conclusions}

We have introduced an additional boron-based ligand system which exhibits some interesting reactivity facilitated by the boron center. The intimate cooperation between the boron and metal centers provides a means of carrying out an unprecedented novel ring opening of norbornadiene. This interesting transformation requires a series of migration steps and the positioning of the boron and metal centers in close proximity to each other. The newly formed boron-ethylenyl cyclopentene unit exhibits an unusual $\eta^{2}-B, C$ coordination motif in which the boron center is weakly interacting with the rhodium center. We have demonstrated for the first time that this functional motif is capable of reacting with dihydrogen to undergo its formal addition across the boron-carbon bond. This could open up a new strategy for the activation of element-element bonds. We have further demonstrated the dehydrogenation and hydrogenation reactivity of the resulting complexes as well as their catalytic application.

\section{Experimental Section}

General remarks. All manipulations were conducted under inert atmosphere using standard Schleck line techniques. Solvents were supplied extra dry from Acros Organics and were stored over $4 \AA$ molecular sieves. $\mathrm{CD}_{3} \mathrm{CN}$ and $\mathrm{C}_{6} \mathrm{D}_{6} \mathrm{NMR}$ solvent was stored in a Young's ampule under $\mathrm{N}_{2}$, over $4 \AA$ molecular sieves and had be degassed through three freeze-pump-thaw cycles prior to use. All reagents were purchased from commercial sources. The rhodium bimetallic precursor $[\mathrm{RhCl}(\mathrm{NBD})]_{2}$ was synthesised according to a published procedure. ${ }^{30}$ All NMR experiments where conducted on a Bruker $400 \mathrm{MHz}$ Ascend ${ }^{\mathrm{TM}}$ 400. Infrared spectra where recorded on a Perkin-Elmer Spectrum Two ATR FT-IR. Mass spectra were recorded by the EPSRC NMSF at Swansea University. Proton $\left({ }^{1} \mathrm{H}\right)$ and carbon $\left({ }^{13} \mathrm{C}\right)$ assignments (Figure 5) were supported by HSQC, HMBC and COSY NMR experiments.

Table 1. Catalytic hydrogenation of olefins with complexes 2 and 3 using $\mathrm{H}_{2}$ gas $^{\mathrm{a}}$ or dimethylamine borane $(\mathrm{AB})^{\mathrm{b}}$ as source of $\mathrm{H}_{2}$

\begin{tabular}{|c|c|c|c|c|}
\hline $\begin{array}{l}\text { Com- } \\
\text { plex }\end{array}$ & $\begin{array}{l}\text { Cat. load- } \\
\text { ing } \\
(\mathrm{mol} \%)^{\mathrm{c}}\end{array}$ & $\begin{array}{c}\text { Source } \\
\text { of } \mathrm{H}_{2}\end{array}$ & Substrate & $\begin{array}{l}\text { Conver- } \\
\text { sion }(\%)^{\mathrm{d}}\end{array}$ \\
\hline 2 & 5.0 & $\mathrm{H}_{2}$ gas & Cyclooctene & $>99$ \\
\hline 2 & 5.0 & $\mathrm{AB}$ & Cyclooctene & 45 \\
\hline 2 & 1.0 & $\mathrm{H}_{2}$ gas & Cyclooctene & 70 \\
\hline 2 & 1.0 & $\mathrm{AB}$ & Cyclooctene & 25 \\
\hline 2 & 0.1 & $\mathrm{H}_{2}$ gas & Cyclooctene & 7 \\
\hline 2 & 0.1 & $\mathrm{AB}$ & Cyclooctene & 19 \\
\hline 2 & 5.0 & $\mathrm{H}_{2}$ gas & Styrene & $>99$ \\
\hline 2 & 5.0 & $\mathrm{AB}$ & Styrene & $>99$ \\
\hline 2 & 1.0 & $\mathrm{H}_{2}$ gas & Styrene & $>99$ \\
\hline 2 & 1.0 & $\mathrm{AB}$ & Styrene & 96 \\
\hline 2 & 0.1 & $\mathrm{H}_{2}$ gas & Styrene & 77 \\
\hline 2 & 0.1 & $\mathrm{AB}$ & Styrene & 47 \\
\hline 3 & 5.0 & $\mathrm{H}_{2}$ gas & Cyclooctene & 69 \\
\hline 3 & 5.0 & $\mathrm{AB}$ & Cyclooctene & 30 \\
\hline 3 & 1.0 & $\mathrm{H}_{2}$ gas & Cyclooctene & 11 \\
\hline 3 & 1.0 & $\mathrm{AB}$ & Cyclooctene & 10 \\
\hline 3 & 0.1 & $\mathrm{H}_{2}$ gas & Cyclooctene & 7 \\
\hline 3 & 5.0 & $\mathrm{H}_{2}$ gas & Styrene & 95 \\
\hline 3 & 5.0 & $\mathrm{AB}$ & Styrene & 95 \\
\hline 3 & 1.0 & $\mathrm{H}_{2}$ gas & Styrene & 59 \\
\hline 3 & 1.0 & $\mathrm{AB}$ & Styrene & 25 \\
\hline 3 & 0.1 & $\mathrm{H}_{2}$ gas & Styrene & 10 \\
\hline
\end{tabular}

a 2.0 bar $\mathrm{H}_{2},{ }^{\text {b }} 4.0$ equivalents of $\mathrm{BH}_{3} \cdot \mathrm{NH}\left(\mathrm{CH}_{3}\right)_{2}$, ${ }^{\text {c Catalysis con- }}$ ducted in $1 \mathrm{~mL} \mathrm{C}_{6} \mathrm{D}_{6},{ }^{\mathrm{d}}$ conversion measure by NMR integration relative to internal standard after $18 \mathrm{~h}$ at $80{ }^{\circ} \mathrm{C}$.

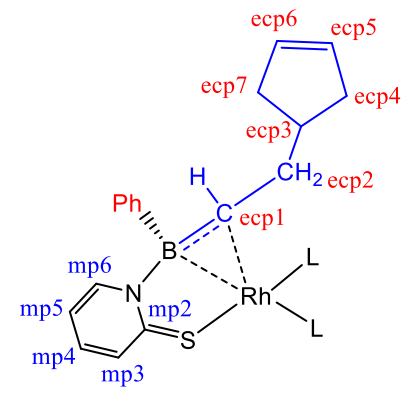

Figure 5. Numbering scheme used for assignments of NMR spectra (see Figure S12.1 in electronic supporting information for assignment of stereochemistry for Complex 2) 
Synthesis of $\mathrm{Li}\left[\mathrm{H}_{2} \mathrm{~B}(\mathrm{Ph})(\mathrm{mp})\right] \cdot \mathbf{0 . 8 5}(\mathrm{THF})$. A Schlenk flask was charged with $\mathrm{Li}\left[\mathrm{H}_{3} \mathrm{~B}(\mathrm{Ph})\right](881.7 \mathrm{mg}, 9.01 \mathrm{mmol})$ and 2-mercaptopyridine (500.7 mg, $4.5 \mathrm{mmol})$. Dry degassed THF (50 mL) was added and the reaction mixture was stirred continuously for 72 hours. After this time, the reaction mixture was filtered into a new Schlenk flask, the solvent volume was reduced to approximately 10 $\mathrm{mL}$ and hexanes $(10 \mathrm{~mL})$ were added to precipitate a small amount of a white solid. The reaction mixture was again filtered and the resulting filtrate was reduced to a few milliliters under reduced pressure. The solid product was obtained as a fine off-white powder upon addition of hexane. The supernatant liquid was removed via cannula filtration and the solid dried under dynamic vacuum. Yield: $873.1 \mathrm{mg}, 3.25 \mathrm{mmol}, 72 \% .{ }^{1} \mathrm{H} \mathrm{NMR} \delta\left(\mathrm{CD}_{3} \mathrm{CN}\right): 6.49\left(\mathrm{t},{ }^{3} J_{\mathrm{HH}}=\right.$ $\left.6.6 \mathrm{~Hz}, 1 \mathrm{H},{ }^{\mathrm{mp} 5} \mathrm{CH}\right), 6.94\left(\mathrm{t},{ }^{3} J_{\mathrm{HH}}=7.2 \mathrm{~Hz}, 1 \mathrm{H},{ }^{p-\mathrm{Ph}} \mathrm{CH}\right), 7.06$ (overlapping m, $3 \mathrm{H},{ }^{m-\mathrm{Ph}} \mathrm{CH}$ and $\left.{ }^{\mathrm{mp} 4} \mathrm{CH}\right), 7.17\left(\mathrm{~d},{ }^{3} J_{\mathrm{HH}}=7.5 \mathrm{~Hz}, 2 \mathrm{H},{ }^{o-}\right.$ $\left.{ }^{\mathrm{Ph}} \mathrm{CH}\right), 7.41\left(\mathrm{~d},{ }^{3} J_{\mathrm{HH}}=8.4 \mathrm{~Hz}, 1 \mathrm{H},{ }^{\mathrm{mp} 3} \mathrm{CH}\right), 7.98\left(\mathrm{~d},{ }^{3} \mathrm{~J}_{\mathrm{HH}}=6.3 \mathrm{~Hz}\right.$, $\left.1 \mathrm{H},{ }^{\mathrm{mp} 6} \mathrm{CH}\right) .{ }^{1} \mathrm{H}\left\{{ }^{11} \mathrm{~B}\right\}$ NMR $\delta\left(\mathrm{CD}_{3} \mathrm{CN}\right): 3.22\left(\mathrm{~s}, 2 \mathrm{H}, \mathrm{BH}_{2}\right) .{ }^{11} \mathrm{~B}$ NMR $\delta\left(\mathrm{CD}_{3} \mathrm{CN}\right):-6.26\left(\mathrm{t},{ }^{1} \mathrm{~J}_{\mathrm{BH}}=92 \mathrm{~Hz}, \mathrm{BH}_{2}\right) .{ }^{11} \mathrm{~B}\left\{{ }^{1} \mathrm{H}\right\} \mathrm{NMR} \delta$ $\left(\mathrm{CD}_{3} \mathrm{CN}\right.$ ): -6.26 (s, h.h.w. $\left.=55 \mathrm{~Hz}, \mathrm{BH}_{2}\right) \cdot{ }^{13} \mathrm{C}\left\{{ }^{1} \mathrm{H}\right\}$ NMR $\delta$ $\left(\mathrm{CD}_{3} \mathrm{CN}\right): 112.9\left(\mathrm{~s},{ }^{\mathrm{mp} 5} \mathrm{C}\right), 124.3\left(\mathrm{~s},{ }^{p-\mathrm{Ph}} \mathrm{C}\right), 127.5\left(\mathrm{~s},{ }^{m-\mathrm{Ph}} \mathrm{C}\right), 133.4$ $\left(\mathrm{s},{ }^{\mathrm{mp}}{ }^{4} \mathrm{C}\right), 134.8\left(\mathrm{~s},{ }^{o-\mathrm{Ph}} \mathrm{C}\right), 135.4\left(\mathrm{~s},{ }^{\mathrm{mp}}{ }^{3} \mathrm{C}\right), 147.6\left(\mathrm{~s},{ }^{\mathrm{mp}} \mathrm{C}\right), 182.4(\mathrm{~s}$, $\left.{ }^{\mathrm{mp}} \mathrm{C}\right)$. IR $\left(\mathrm{cm}^{-1}\right.$, ATR powder film) $2263 \mathrm{w}(\mathrm{B}-\mathrm{H})$. FTMS -p NSI: $m / z, 200.0715$ [M-Li] ${ }^{-}$. Accurate Mass: $\left(\mathrm{C}_{11} \mathrm{H}_{11} \mathrm{~N}_{1}{ }^{10} \mathrm{~B}_{1} \mathrm{~S}_{1}\right) m_{\text {calc }}=$ 199.0747 Da, $m_{\text {exp }}=199.0751 \mathrm{Da}$.

Synthesis of $\operatorname{Li}\left[\mathbf{D}_{2} \mathbf{B}(\mathbf{P h})(\mathbf{m p})\right]$. The deuterated analogue of the ligand was prepared through an identical synthesis to that described for the $\operatorname{Li}\left[\mathrm{H}_{2} \mathrm{~B}(\mathrm{Ph})(\mathrm{mp})\right]$, with $\operatorname{Li}\left[\mathrm{D}_{3} \mathrm{~B}(\mathrm{Ph})\right]$ used in place of $\mathrm{Li}\left[\mathrm{H}_{3} \mathrm{~B}(\mathrm{Ph})\right] .{ }^{11} \mathrm{~B}$ NMR $\delta\left(\mathrm{C}_{6} \mathrm{D}_{6}\right):-6.82$ (bs, h.h.w. $\left.=90 \mathrm{~Hz}, \mathrm{BD}_{2}\right)$.

Synthesis of $\left[R h\left\{\kappa^{3}-S, H, H-H_{2} B(P h)(m p)\right\}(N B D)\right]$ (1). A Schlenk flask was charged with $[\mathrm{RhCl}(\mathrm{NBD})]_{2}(100 \mathrm{mg}, 0.217$ mmol) which was fully dissolved in $20 \mathrm{~mL}$ of DCM. $\mathrm{Li}\left[\mathrm{H}_{2} \mathrm{~B}(\mathrm{Ph})(\mathrm{mp})\right] \cdot 0.85 \mathrm{THF}(116.4 \mathrm{mg}, 0.434 \mathrm{mmol})$ was added to the solution. The reaction mixture was continuously stirred and allowed to react for $1 \mathrm{~h}$ before being filtered into another Schlenk flask. The solvent was removed under reduced pressure and the residue extracted with hexane $(20 \mathrm{~mL})$. The hexane was removed under reduced pressure and the solid product was dried under dynamic vacuum. Yield: $142.1 \mathrm{mg}, 0.360 \mathrm{mmol}, 83 \% .{ }^{1} \mathrm{H}$ NMR $\delta$ $\left(\mathrm{C}_{6} \mathrm{D}_{6}\right): 1.07$ (s, $\left.2 \mathrm{H},{ }^{\mathrm{NBD}} \mathrm{CH}_{2}\right), 3.28\left(\mathrm{~s}, 2 \mathrm{H},{ }^{\mathrm{NBD}} \mathrm{CH}\right), 3.94(\mathrm{~s}, 4 \mathrm{H}$, $\left.{ }^{\mathrm{NBD}} \mathrm{CH}\right), 5.80\left(\tau \mathrm{d},{ }^{3} J_{\mathrm{HH}}=6.7 \mathrm{~Hz},{ }^{4} J_{\mathrm{HH}}=1.4 \mathrm{~Hz}, 1 \mathrm{H},{ }^{\mathrm{mp} 5} \mathrm{CH}\right), 6.38$ $\left(\tau \mathrm{d},{ }^{3} J_{\mathrm{HH}}=7.6 \mathrm{~Hz},{ }^{4} J_{\mathrm{HH}}=1.2 \mathrm{~Hz}, 1 \mathrm{H},{ }^{\mathrm{mp} 4} \mathrm{CH}\right), 7.24\left(\mathrm{t},{ }^{3} J_{\mathrm{HH}}=7.4\right.$ $\left.\mathrm{Hz}, 1 \mathrm{H},{ }^{p-\mathrm{Ph}} \mathrm{CH}\right), 7.35\left(\mathrm{t},{ }^{3} J_{\mathrm{HH}}=7.4 \mathrm{~Hz}, 2 \mathrm{H},{ }^{m-\mathrm{Ph}} \mathrm{CH}\right), 7.58\left(\mathrm{dt},{ }^{3} J_{\mathrm{HH}}\right.$ $\left.=8.7 \mathrm{~Hz},{ }^{4} J_{\mathrm{HH}}=1.1 \mathrm{~Hz}, 1 \mathrm{H},{ }^{\mathrm{mp} 3} \mathrm{CH}\right), 7.61\left(\mathrm{~d},{ }^{3} J_{\mathrm{HH}}=7.4 \mathrm{~Hz}, 2 \mathrm{H},{ }^{\mathrm{o}}\right.$ $\left.{ }^{\mathrm{Ph}} \mathrm{CH}\right), 7.87\left(\mathrm{~d},{ }^{3} J_{\mathrm{HH}}=6.5 \mathrm{~Hz}, 1 \mathrm{H},{ }^{\mathrm{mp} 6} \mathrm{CH}\right) .{ }^{1} \mathrm{H}\left\{{ }^{11} \mathrm{~B}\right\} \mathrm{NMR} \delta\left(\mathrm{C}_{6} \mathrm{D}_{6}\right)$ : $-1.59\left(\mathrm{~d},{ }^{1} J_{\mathrm{RhH}}=2 \mathrm{~Hz}, \mathrm{BH}_{2}\right) .{ }^{11} \mathrm{~B}$ NMR $\delta\left(\mathrm{C}_{6} \mathrm{D}_{6}\right): 0.95\left(\mathrm{t},{ }^{1} J_{\mathrm{BH}}=62\right.$ $\mathrm{Hz}) .{ }^{11} \mathrm{~B}\left\{{ }^{1} \mathrm{H}\right\}$ NMR $\delta\left(\mathrm{C}_{6} \mathrm{D}_{6}\right): 0.95$ (s, h.h.w. $\left.=70 \mathrm{~Hz}\right) \cdot{ }^{13} \mathrm{C}\left\{{ }^{1} \mathrm{H}\right\}$ NMR $\delta\left(\mathrm{C}_{6} \mathrm{D}_{6}\right): 49.0\left(\mathrm{~s},{ }^{\mathrm{NBD}} \mathrm{CH}\right), 62.0\left(\mathrm{~d},{ }^{3} J_{\mathrm{RhC}}=5.3 \mathrm{~Hz},{ }^{\mathrm{NBD}} \mathrm{CH}_{2}\right)$, $114.7\left(\mathrm{~s},{ }^{\mathrm{mp} 5} \mathrm{C}\right), 127.2\left(\mathrm{~s},{ }^{p-\mathrm{Ph}} \mathrm{CH}\right), 128.5\left(\mathrm{~s},{ }^{m-\mathrm{Ph}} \mathrm{CH}\right), 128.9\left(\mathrm{~d},{ }^{3} J_{\mathrm{RhC}}\right.$ $\left.=1.5 \mathrm{~Hz},{ }^{\mathrm{mp}} \mathrm{C}\right), 132.3\left(\mathrm{~s},{ }^{\mathrm{mp} 4} \mathrm{C}\right), 136.6\left(\mathrm{~s},{ }^{o-\mathrm{Ph}} \mathrm{CH}\right), 143.9\left(\mathrm{~s},{ }^{\mathrm{mp}} \mathrm{C}\right)$, $175.1\left(\mathrm{~d},{ }^{2} J_{\mathrm{RhC}}=1.8,{ }^{\mathrm{mp} 2} \mathrm{C}\right)$. IR $\left(\mathrm{cm}^{-1}\right.$, ATR powder film) $1827 \mathrm{w}$ $\left(\mathrm{BH}_{2} \mathrm{Rh}\right) .+\mathrm{p}$ EI MS: $m / z 395.0[\mathrm{M}]^{+}$. Accurate Mass: $\left(\mathrm{C}_{18} \mathrm{H}_{19} \mathrm{~N}_{1}{ }^{10} \mathrm{~B}_{1} \mathrm{Rh}_{1} \mathrm{~S}_{1}\right) m_{\text {calc }}=394.0417 \mathrm{Da}, m_{\text {exp }}=394.0419 \mathrm{Da}$.

Synthesis of $\left[R h\left\{\kappa^{3}-S, D, D-D_{2} B(P h)(m p)\right\}(N B D)\right]\left(1-d_{2}\right)$. This complex was synthesized in a similar manner to the non-deuterated analogue, Complex 1 , by the addition of 2 equiv. of $\mathrm{Li}\left[\mathrm{D}_{2} \mathrm{~B}(\mathrm{Ph})(\mathrm{mp})\right]$ to $[\mathrm{RhCl}(\mathrm{NBD})]_{2}{ }^{2} \mathrm{D} \mathrm{NMR} \delta\left(\mathrm{C}_{6} \mathrm{D}_{6}\right):-1.58(\mathrm{bs}$, $\left.\mathrm{BD}_{2}\right) .{ }^{11} \mathrm{~B}$ NMR $\delta\left(\mathrm{C}_{6} \mathrm{D}_{6}\right): 0.44$ (s, h.h.w. $\left.=90 \mathrm{~Hz}, \mathrm{BD}_{2}\right)$.

Synthesis of $\left[\mathrm{Rh}\left\{\kappa^{2}-S, B-B(P h)(m p)\left(\mathrm{CHCH}_{2} \mathrm{C}_{5} \mathrm{H}_{7}\right)\right\}\left(\mathrm{PPh}_{3}\right)_{2}\right]$ (2). A Schlenk flask was charged with $\left[\mathrm{Rh}\left\{\kappa^{3}-S, H, H-\right.\right.$ $\left.\left.\mathrm{H}_{2} \mathrm{~B}(\mathrm{Ph})(\mathrm{mp})\right\}(\mathrm{NBD})\right](50 \mathrm{mg}, 0.127 \mathrm{mmol})$ and $\mathrm{PPh}_{3}(66.4 \mathrm{mg}$, $0.253 \mathrm{mmol})$. Benzene $(10 \mathrm{~mL})$ was added to the flask and the reaction mixture was continuously stirred for $1 \mathrm{~h}$. The solvent was thereafter minimized to approximately $2 \mathrm{~mL}$ under reduced pressure. Hexane $(20 \mathrm{~mL})$ was subsequently added to precipitate out an orange/brown solid. The solid was separated from the supernatant via cannula filtration before being dried under dynamic vacuum. Yield: $88.5 \mathrm{mg}, 0.096 \mathrm{mmol}, 76 \% .{ }^{1} \mathrm{H}$ NMR $\delta\left(\mathrm{C}_{6} \mathrm{D}_{6}\right): 1.83(\mathrm{~m}, 1 \mathrm{H}$, $\left.{ }^{\text {ecp4a }} \mathrm{CH}_{2}\right), 2.03\left(\mathrm{~m}, 1 \mathrm{H},{ }^{\text {ecp } 7 \mathrm{~b}} \mathrm{CH}_{2}\right), 2.05\left(\mathrm{~m}, 1 \mathrm{H},{ }^{\text {ecp } 3} \mathrm{CH}\right), 2.29(\mathrm{~m}$, $\left.1 \mathrm{H},{ }^{\text {ecp4b }} \mathrm{CH}_{2}\right), 2.42\left(\mathrm{~m}, 1 \mathrm{H},{ }^{\text {ecp } 7 \mathrm{a}} \mathrm{CH}_{2}\right), 2.56\left(\mathrm{~m}, 1 \mathrm{H},{ }^{\text {ecp2b }} \mathrm{CH}_{2}\right), 2.84$ $\left(\mathrm{m}, 1 \mathrm{H},{ }^{\text {ecp2a }} \mathrm{CH}_{2}\right), 3.13\left(\mathrm{~m}, 1 \mathrm{H},{ }^{\text {ecp } 1} \mathrm{CH}\right), 5.58\left(\mathrm{~m}, 1 \mathrm{H},{ }^{\text {ecp }} \mathrm{CH}\right), 5.67$ $\left(\mathrm{m}, 1 \mathrm{H},{ }^{\mathrm{ecp} 5} \mathrm{CH}\right), 5.68\left(\tau \mathrm{d},{ }^{3} J_{\mathrm{HH}}=6.7 \mathrm{~Hz},{ }^{4} J_{\mathrm{HH}}=1.2 \mathrm{~Hz}, 1 \mathrm{H},{ }^{\mathrm{mp}}{ }^{5} \mathrm{CH}\right)$, $6.19\left(\tau \mathrm{d},{ }^{3} J_{\mathrm{HH}}=6.9 \mathrm{~Hz},{ }^{4} J_{\mathrm{HH}}=1.6 \mathrm{~Hz}, 1 \mathrm{H},{ }^{\mathrm{mp} 4} \mathrm{CH}\right), 6.79\left(\mathrm{~d},{ }^{3} J_{\mathrm{HH}}=\right.$ $\left.8.6 \mathrm{~Hz}, 1 \mathrm{H},{ }^{\mathrm{mp} 3} \mathrm{CH}\right), 6.89\left(\mathrm{~m}, 9 \mathrm{H},{ }^{\mathrm{PPh}} \mathrm{CH}\right), 6.93\left(\mathrm{~m}, 9 \mathrm{H},{ }^{\mathrm{PPh}} \mathrm{CH}\right), 7.16$ $\left(\mathrm{d},{ }^{3} \mathrm{~J}_{\mathrm{HH}}=5.6 \mathrm{~Hz}, 1 \mathrm{H},{ }^{\mathrm{mp} 6} \mathrm{CH}\right), 7.36$ (unresolved, $\left.1 \mathrm{H},{ }^{\mathrm{Ph}} \mathrm{CH}\right), 7.39$ (unresolved, $2 \mathrm{H},{ }^{\mathrm{Ph}} \mathrm{CH}$ ), $7.54\left(\mathrm{t},{ }^{3} \mathrm{~J}_{\mathrm{HH}}=8.4 \mathrm{~Hz}, 6 \mathrm{H},{ }^{\mathrm{PPh}} \mathrm{CH}\right.$ ), 7.66 (unresolved, 2H, $\left.{ }^{\mathrm{Ph}} \mathrm{CH}\right), 7.66\left(\mathrm{t}, 6 \mathrm{H},{ }^{\mathrm{PPh}} \mathrm{CH}\right) .{ }^{11} \mathrm{~B} \mathrm{NMR} \delta\left(\mathrm{C}_{6} \mathrm{D}_{6}\right)$ : 34.7 (bs, h.h.w. $=1550 \mathrm{~Hz}, \mathrm{~B}=\mathrm{C}) .{ }^{11} \mathrm{~B}\left\{{ }^{1} \mathrm{H}\right\}$ NMR $\delta\left(\mathrm{C}_{6} \mathrm{D}_{6}\right): 34.7$ (bs, h.h.w. $=1550 \mathrm{~Hz}, \mathrm{~B}=\mathrm{C}) \cdot{ }^{31} \mathrm{P}\left\{{ }^{1} \mathrm{H}\right\}$ NMR $\delta\left(\mathrm{C}_{6} \mathrm{D}_{6}\right): 31.90(\mathrm{dd}$, $\left.{ }^{1} J_{\mathrm{RhP}}=134.2 \mathrm{~Hz},{ }^{2} J_{\mathrm{PP}}=32.6 \mathrm{~Hz}\right) .47 .75\left(\mathrm{dd},{ }^{1} J_{\mathrm{RhP}}=175.8 \mathrm{~Hz},{ }^{2} J_{\mathrm{PP}}\right.$ $=33.2 \mathrm{~Hz}) \cdot{ }^{13} \mathrm{C}\left\{{ }^{1} \mathrm{H}\right\}$ NMR $\delta\left(\mathrm{C}_{6} \mathrm{D}_{6}\right): 39.36\left(\mathrm{~s},{ }^{\mathrm{ecp} 4} \mathrm{CH}_{2}\right), 39.38(\mathrm{~s}$, $\left.{ }^{\text {ecp7 }} \mathrm{CH}_{2}\right), 41.4\left(\mathrm{~d},{ }^{\text {ecp }}{ }^{2} \mathrm{CH}_{2}\right), 42.9\left(\mathrm{~d},{ }^{\text {ecp } 3} \mathrm{CH}\right), 58.1$ (Assigned through HSQC,$\left.{ }^{\text {ecp } 1} \mathrm{CH}\right), 113.9\left(\mathrm{~s},{ }^{\mathrm{mp} 7} \mathrm{CH}\right), 126.7\left(\mathrm{~s},{ }^{\mathrm{Ph}} \mathrm{C}\right), 127.3\left[\mathrm{~d}, J_{\mathrm{PC}}=9.1\right.$ $\left.\mathrm{Hz},, \mathrm{P}\left(\mathrm{C}_{6} \mathrm{H}_{5}\right)_{3}\right], 127.8$ (unresolved, ${ }^{\mathrm{Ph}} \mathrm{C}$ ), 128.6 (unresolved, $\left.{ }^{m p 3} \mathrm{CH}\right), 128.6$ [unresolved, $\mathrm{P}\left(\mathrm{C}_{6} \mathrm{H}_{5}\right)_{3}$ ], 128.8 [unresolved, $\left.\mathrm{P}\left(\mathrm{C}_{6} \mathrm{H}_{5}\right)_{3}\right], 130.3\left(\mathrm{~s},{ }^{\text {ecp }} \mathrm{CH}\right), 130.6\left(\mathrm{~s},{ }^{\mathrm{ecp} 5} \mathrm{CH}\right), 134.4\left(\mathrm{~s},{ }^{\mathrm{Ph}} \mathrm{C}\right), 135.4$ $\left[\mathrm{d}, J_{\mathrm{PC}}=12.4 \mathrm{~Hz}, \mathrm{P}\left(\mathrm{C}_{6} \mathrm{H}_{5}\right)_{3}\right], 135.5\left(\mathrm{~s},{ }^{\mathrm{mp} 4} \mathrm{CH}\right), 135.8\left[\mathrm{~d}, J_{\mathrm{PC}}=11.7\right.$ $\left.\mathrm{Hz}, \mathrm{P}\left(\mathrm{C}_{6} \mathrm{H}_{5}\right)_{3}\right], 136.8\left[\mathrm{~d}, J_{\mathrm{PC}}=32.5 \mathrm{~Hz}, i-\mathrm{P}\left(\mathrm{C}_{6} \mathrm{H}_{5}\right)_{3}\right], 137.8\left[\mathrm{~d}, J_{\mathrm{PC}}=\right.$ $\left.36.5 \mathrm{~Hz}, i-\mathrm{P}\left(\mathrm{C}_{6} \mathrm{H}_{5}\right)_{3}\right], 142.8\left(\mathrm{~s},{ }^{\mathrm{mp} 6} \mathrm{CH}\right), 147.7(\mathrm{bs}$, assigned through $\left.\mathrm{HMBC},{ }^{i-\mathrm{Ph}} \mathrm{C}\right), 177.4\left(\mathrm{dd},{ }^{2} J_{\mathrm{RhC}}=15.1 \mathrm{~Hz},{ }^{3} J_{\mathrm{PC}}=2.3 \mathrm{~Hz},{ }^{\mathrm{mp}}{ }^{2} \mathrm{C}\right) . \mathrm{IR}$ $\left(\mathrm{cm}^{-1}\right.$, ATR powder film) 3050, 1426. + p EI MS: $\mathrm{m} / z 737.1[\mathrm{M}-$ $\left.\mathrm{B}(\mathrm{Ph})\left(\mathrm{C}_{7} \mathrm{H}_{10}\right)\right]^{+}, 720.1[\mathrm{M}-\mathrm{B}(\mathrm{Ph})(\mathrm{mp})]^{+}$.

Synthesis of $\quad\left[\mathrm{Rh}\left\{\kappa^{2}-S, B-B(P h)(\mathrm{mp})(\mathrm{CHCH}-\right.\right.$

$\left.\left.\left.\mathrm{DC}_{5} \mathbf{H}_{6} \mathbf{D}\right)\right\}(\mathbf{P P h})_{2}\right]$ (2-d2). This complex was synthesized in a similar manner to the non-deuterated analogue, Complex 2 , by the addition of 2 equiv. of $\mathrm{PPh}_{3}$ to complex 1-d 2 in benzene. ${ }^{2} \mathrm{D}$ NMR $\delta$ ( $\left.\mathrm{C}_{6} \mathrm{D}_{6}\right): 1.98$ (bs, $\left.{ }^{\text {ecp7b }}{ }^{\mathrm{C}} \mathrm{HD}\right), 2.79$ (bs, ${ }^{\mathrm{ec} 2 \mathrm{a}} \mathrm{CHD}$ ).

Synthesis of $\left[\mathrm{Rh}\left\{\kappa^{2}-S, B-B(P h)(m p)\left(\mathrm{CHCH}_{2} \mathrm{C}_{5} \mathrm{H}_{7}\right)\right\}(\mathrm{CO})-\right.$ $\left.\left(\mathbf{P P h}_{3}\right)\right]$ (3). A Schlenk flask was charged with $\left[\mathrm{Rh}\left\{\kappa^{3}-S, H, H-\right.\right.$ $\left.\left.\mathrm{H}_{2} \mathrm{~B}(\mathrm{Ph})(\mathrm{mp})\right\}(\mathrm{NBD})\right](50 \mathrm{mg}, 0.127 \mathrm{mmol})$ and $\mathrm{PPh}_{3}(66.4 \mathrm{mg}$, $0.253 \mathrm{mmol})$. Benzene $(10 \mathrm{~mL})$ was added to the flask and the reaction mixture was continuously stirred for $1 \mathrm{~h}$. Once this time had elapsed the reaction mixture was freeze-pump-thaw degassed, and the headspace was filled with $\mathrm{CO}$ gas. The reaction mixture was left stirring for $24 \mathrm{~h}$ before the solvent was removed under reduced pressure. The pure product was obtained as a yellow solid after recrystallization from diethyl ether. Yield: $53.4 \mathrm{mg}, 0.078 \mathrm{mmol}$, 61\%. ${ }^{1} \mathrm{H}$ NMR $\delta\left(\mathrm{C}_{6} \mathrm{D}_{6}\right): 2.17\left(\mathrm{~m}, 1 \mathrm{H},{ }^{\text {ecp }} \mathrm{CH}_{2}\right), 2.23(\mathrm{~m}, 1 \mathrm{H}$, $\left.{ }^{\text {ecp }} \mathrm{CH}_{2}\right), 2.28\left(\mathrm{~m}, 1 \mathrm{H},{ }^{\text {ecp }} \mathrm{CH}_{2}\right), 2.62\left(\mathrm{~m}, 1 \mathrm{H},{ }^{\text {ecp }} \mathrm{CH}_{2}\right), 2.68(\mathrm{~m}, 1 \mathrm{H}$, $\left.{ }^{\text {ecp }} \mathrm{CH}_{2}\right), 2.69\left(\mathrm{~m}, 1 \mathrm{H},{ }^{\text {ecp }} \mathrm{CH}_{2}\right), 2.84\left(\mathrm{~m}, 1 \mathrm{H},{ }^{\text {ecp }} \mathrm{CH}\right), 4.82(\mathrm{~m}, 1 \mathrm{H}$, $\left.{ }^{\mathrm{ecp} 1} \mathrm{CH}\right), 5.71\left(\mathrm{~s}, 2 \mathrm{H},{ }^{\mathrm{ecp} 5,6} \mathrm{CH}\right), 5.82\left(\tau \mathrm{d},{ }^{3} J_{\mathrm{HH}}=6.7 \mathrm{~Hz}, 1 \mathrm{H},{ }^{\mathrm{mp} 5} \mathrm{CH}\right)$, $6.29\left(\tau \mathrm{d},{ }^{3} J_{\mathrm{HH}}=7.2 \mathrm{~Hz},{ }^{4} J_{\mathrm{HH}}=1.6 \mathrm{~Hz}, 1 \mathrm{H},{ }^{\mathrm{mp}}{ }^{4} \mathrm{CH}\right), 6.84\left(\mathrm{~d},{ }^{3} J_{\mathrm{HH}}=\right.$ $\left.8.5 \mathrm{~Hz}, 1 \mathrm{H},{ }^{\mathrm{mp} 3} \mathrm{CH}\right), 7.01\left(\mathrm{~m}, 9 \mathrm{H},{ }^{m / p-\mathrm{PPh}} \mathrm{CH}\right), 7.17\left(\mathrm{~d}, 1 \mathrm{H},{ }^{\mathrm{mp} 6} \mathrm{CH}\right)$, $7.21\left(\mathrm{t},{ }^{3} J_{\mathrm{HH}}=7.3 \mathrm{~Hz}, 1 \mathrm{H},{ }^{p-\mathrm{Ph}} \mathrm{CH}\right), 7.31\left(\mathrm{t},{ }^{3} J_{\mathrm{HH}}=7.5 \mathrm{~Hz}, 2 \mathrm{H},{ }^{m-}\right.$ $\left.{ }^{\mathrm{Ph}} \mathrm{CH}\right), 7.66\left(\mathrm{~m}, 6 \mathrm{H},{ }^{o-\mathrm{PPh}} \mathrm{CH}\right), 7.68\left(\mathrm{~d}, 2 \mathrm{H},{ }^{o-\mathrm{Ph}} \mathrm{CH}\right) .{ }^{11} \mathrm{~B}$ NMR $\delta$ $\left(\mathrm{C}_{6} \mathrm{D}_{6}\right)$ : 33.8 (bs, h.h.w. $\left.=600 \mathrm{~Hz}, \mathrm{BPh}\right){ }^{11} \mathrm{~B}\left\{{ }^{1} \mathrm{H}\right\} \mathrm{NMR} \delta\left(\mathrm{C}_{6} \mathrm{D}_{6}\right)$ : 33.8 (bs, h.h.w. $=600 \mathrm{~Hz}, \mathrm{BPh}) .{ }^{31} \mathrm{P}\left\{{ }^{1} \mathrm{H}\right\}$ NMR $\delta\left(\mathrm{C}_{6} \mathrm{D}_{6}\right): 31.95(\mathrm{~d}$, $\left.{ }^{1} \mathrm{~J}_{\mathrm{RhP}}=132.9 \mathrm{~Hz}\right) .{ }^{13} \mathrm{C}\left\{{ }^{1} \mathrm{H}\right\} \mathrm{NMR} \delta\left(\mathrm{C}_{6} \mathrm{D}_{6}\right): 39.4\left(\mathrm{~s},{ }^{\text {ecp }} \mathrm{CH}\right), 40.0(\mathrm{~s}$, $\left.{ }^{\text {ecp }} \mathrm{CH}\right), 40.3\left(\mathrm{~s},{ }^{\text {ecp }} \mathrm{CH}\right), 41.3\left(\mathrm{~s},{ }^{\text {ecp } 3} \mathrm{CH}\right), 61.9$ (bs, assigned through HSQC, $\left.{ }^{\text {ecp } 1} \mathrm{CH}\right), 115.9\left(\mathrm{~s},{ }^{\mathrm{mp}} \mathrm{CH}\right), 127.2\left(\mathrm{~s},{ }^{p-\mathrm{Ph}} \mathrm{C}\right), 128.2$ (unresolved, $\left.{ }^{m-\mathrm{Ph}} \mathrm{C}\right), 128.4$ [unresolved, $\mathrm{P}\left(\mathrm{C}_{6} \mathrm{H}_{5}\right)_{3}$ ], $129.4\left(\mathrm{~d},{ }^{3} J_{\mathrm{RhC}}=2.2\right.$ $\left.\mathrm{Hz},{ }^{\mathrm{mp} 3} \mathrm{CH}\right), 129.9\left[\mathrm{~d}, J_{\mathrm{PC}}=2.0 \mathrm{~Hz}, \mathrm{P}\left(\mathrm{C}_{6} \mathrm{H}_{5}\right)_{3}\right], 130.4\left(\mathrm{~d}, J_{\mathrm{RhC}}=35.6\right.$ $\left.\mathrm{Hz},{ }^{\text {ecp5 } 56} \mathrm{C}\right), 133.0\left(\mathrm{~s},{ }^{o-\mathrm{Ph}} \mathrm{C}\right), 134.5\left[\mathrm{~d},{ }^{1} J_{\mathrm{PC}}=40.4, i-\mathrm{P}\left(\mathrm{C}_{6} \mathrm{H}_{5}\right)_{3}\right]$, $134.9\left[\mathrm{~d},{ }^{2} J_{\mathrm{PC}}=12.7 \mathrm{~Hz}, o-\mathrm{P}\left(\mathrm{C}_{6} \mathrm{H}_{5}\right)_{3}\right], 136.8\left(\mathrm{~s},{ }^{\mathrm{mp}}{ }^{4} \mathrm{CH}\right), 143.0(\mathrm{~s}$, $\left.{ }^{\mathrm{mp}}{ }^{6} \mathrm{CH}\right), 144.3$ (bs, assigned through $\left.\mathrm{HMBC},{ }^{i-\mathrm{Ph}} \mathrm{C}\right), 177.4\left(\mathrm{dd},{ }^{2} J_{\mathrm{RhC}}\right.$ $\left.=17.0 \mathrm{~Hz},{ }^{\mathrm{mp}}{ }^{2} \mathrm{C}\right), 193.3\left(\mathrm{dd},{ }^{1} J_{\mathrm{RhC}}=72.2 \mathrm{~Hz},{ }^{2} J_{\mathrm{PC}}=14.9 \mathrm{~Hz}, \mathrm{CO}\right)$. IR $\left(\mathrm{cm}^{-1}\right.$, ATR powder film) 1945 (CO). + p EI MS: $\mathrm{m} / z 685.0$ 
$[\mathrm{M}]^{+}, 657.0[\mathrm{M}-(\mathrm{CO})]^{+}, 563.0\left[\mathrm{M}-(\mathrm{CO})-\left(\mathrm{C}_{7} \mathrm{H}_{10}\right)\right]^{+}$. Accurate Mass: $\left(\mathrm{C}_{37} \mathrm{H}_{34} \mathrm{O}_{1} \mathrm{~N}_{1}{ }^{10} \mathrm{~B}_{1} \mathrm{P}_{1} \mathrm{Rh}_{1} \mathrm{~S}_{1}\right) m_{\text {calc }}=684.1278 \mathrm{Da}, m_{\text {exp }}=$ $684.1278 \mathrm{Da} ;\left(\mathrm{C}_{36} \mathrm{H}_{34} \mathrm{~N}_{1}{ }^{10} \mathrm{~B}_{1} \mathrm{P}_{1} \mathrm{Rh}_{1} \mathrm{~S}_{1}\right) m_{\text {calc }}=656.1328 \mathrm{Da}, m_{\text {exp }}=$ 656.1329 Da.

Synthesis of $\quad\left[\mathrm{Rh}\left\{\kappa^{2}-\mathrm{S}, \mathrm{H}-\mathrm{HB}(\mathrm{Ph})(\mathrm{mp})\left(\mathrm{CH}_{2} \mathrm{CH}_{2} \mathrm{C}\right.\right.\right.$. $\left.\left.\left.{ }_{5} \mathbf{H}_{7}\right)\right\}\left(\mathbf{P P h}_{3}\right)_{2}\right]$ (5). A Young's NMR tube was charged with $\left[\mathrm{Rh}\left\{\kappa^{2}-\right.\right.$ $\left.\left.S, H-\mathrm{HB}(\mathrm{Ph})(\mathrm{mp})\left(\mathrm{CH}_{2} \mathrm{CH}_{2} \mathrm{C}_{5} \mathrm{H}_{7}\right)\right\}\left(\mathrm{PPh}_{3}\right)_{2}\right]\left(3 \mathrm{mg}, \quad 3.26 \times 10^{-3}\right.$ $\mathrm{mmol}$ ) and dissolved in $0.8 \mathrm{~mL}$ of benzene- $\mathrm{d}_{6}$. The resulting solution was degassed through three consecutive freeze-pump-thaw cycles before the headspace was subsequently filled with $\mathrm{H}_{2}$. The reaction mixture was left to react for 30 minutes before the NMR of the product was recorded. ${ }^{1} \mathrm{H}$ NMR $\delta\left(\mathrm{C}_{6} \mathrm{D}_{6}\right):-6.88$ (bd, h.h.w. $=$ $90 \mathrm{~Hz}, 1 \mathrm{H}, \mathrm{BH}), 0.56\left(\mathrm{td},{ }^{3} J_{\mathrm{HH}}=13.6 \mathrm{~Hz}, 1 \mathrm{H},{ }^{\mathrm{ecp} 1} \mathrm{CH}_{2}\right), 0.70(\mathrm{td}$, $\left.{ }^{3} J_{\mathrm{HH}}=13.6 \mathrm{~Hz}, 1 \mathrm{H},{ }^{\text {ecp }}{ }^{1} \mathrm{CH}_{2}\right), 1.12\left(\mathrm{~m}, 1 \mathrm{H},{ }^{\text {ecp } 2} \mathrm{CH}_{2}\right), 1.56(\mathrm{~m}, 1 \mathrm{H}$, $\left.{ }^{\text {ecp } 2} \mathrm{CH}_{2}\right), 1.89\left(\mathrm{~m}, 2 \mathrm{H},{ }^{\text {epc } 4,7} \mathrm{CH}_{2}\right), 2.10\left(\mathrm{~m}, 1 \mathrm{H},{ }^{\text {ecp } 3} \mathrm{CH}\right), 2.47(\mathrm{~m}$, $\left.2 \mathrm{H},{ }^{\text {epc } 4,7} \mathrm{CH}_{2}\right), 5.69\left(\mathrm{~s}, 2 \mathrm{H},{ }^{\text {ecp} 5,6} \mathrm{CH}\right), 5.81\left(\tau \mathrm{d},{ }^{3} J_{\mathrm{HH}}=6.7 \mathrm{~Hz},{ }^{4} J_{\mathrm{HH}}\right.$ $\left.=1.2 \mathrm{~Hz}, 1 \mathrm{H},{ }^{\mathrm{mp} 5} \mathrm{CH}\right), 6.19\left(\tau \mathrm{d},{ }^{3} J_{\mathrm{HH}}=6.9 \mathrm{~Hz},{ }^{4} J_{\mathrm{HH}}=1.5 \mathrm{~Hz}, 1 \mathrm{H}\right.$, $\left.{ }^{\mathrm{mp} 4} \mathrm{CH}\right), 6.91\left(\mathrm{~m}, 18 \mathrm{H},{ }^{\mathrm{PPh}} \mathrm{CH}\right), 7.27\left(\mathrm{~d}, 1 \mathrm{H},{ }^{\mathrm{mp} 3} \mathrm{CH}\right), 7.29(\mathrm{~m}, 5 \mathrm{H}$, $\left.{ }^{\mathrm{PPh}} \mathrm{CH}\right), 7.50\left(\mathrm{~d},{ }^{3} \mathrm{~J}_{\mathrm{HH}}=6.4 \mathrm{~Hz}, 1 \mathrm{H},{ }^{\mathrm{mp} 6} \mathrm{CH}\right), 7.59\left(\mathrm{~m}, 6 \mathrm{H},{ }^{\mathrm{PPh}} \mathrm{CH}\right)$, $7.65\left(\mathrm{~m}, 6 \mathrm{H},{ }^{\mathrm{PPh}} \mathrm{CH}\right) .{ }^{1} \mathrm{H}\left\{{ }^{11} \mathrm{~B}\right\} \mathrm{NMR} \delta\left(\mathrm{C}_{6} \mathrm{D}_{6}\right):-6.88\left(\mathrm{ddd},{ }^{1} J_{\mathrm{RhH}}=\right.$ $\left.45.5 \mathrm{~Hz},{ }^{3} J_{\mathrm{PH}}=20.6 \mathrm{~Hz},{ }^{3} J_{\mathrm{PH}}=8.9 \mathrm{~Hz}, 1 \mathrm{H}, \mathrm{BH}\right) .{ }^{1} \mathrm{H}\left\{{ }^{31} \mathrm{P}\right\} \mathrm{NMR} \delta$ $\left(\mathrm{C}_{6} \mathrm{D}_{6}\right):-6.88\left(\mathrm{bd},{ }^{1} J_{\mathrm{RhH}}=20.8 \mathrm{~Hz}, 1 \mathrm{H}, \mathrm{BH}\right) .{ }^{11} \mathrm{~B}$ NMR $\delta\left(\mathrm{C}_{6} \mathrm{D}_{6}\right)$ : 5.5 (bs, h.h.w. $=720 \mathrm{~Hz}, \mathrm{BH}) .{ }^{11} \mathrm{~B}\left\{{ }^{1} \mathrm{H}\right\}$ NMR $\delta\left(\mathrm{C}_{6} \mathrm{D}_{6}\right): 5.5(\mathrm{bs}$, h.h.w. $=690 \mathrm{~Hz}, \mathrm{BH}) .{ }^{31} \mathrm{P}\left\{{ }^{1} \mathrm{H}\right\} \mathrm{NMR} \delta\left(\mathrm{C}_{6} \mathrm{D}_{6}\right): 38.6\left(\mathrm{dd},{ }^{1} \mathrm{~J}_{\mathrm{RhP}}=\right.$ $\left.168.0 \mathrm{~Hz},{ }^{2} \mathrm{~J}_{\mathrm{PP}}=45.3 \mathrm{~Hz}, \mathrm{PPh}_{3}\right), 45.5\left(\mathrm{dd},{ }^{1} \mathrm{~J}_{\mathrm{RhP}}=182.7 \mathrm{~Hz},{ }^{2} \mathrm{~J}_{\mathrm{PP}}=\right.$ $\left.45.1 \mathrm{~Hz}, \mathrm{PPh}_{3}\right) .{ }^{13} \mathrm{C}\left\{{ }^{1} \mathrm{H}\right\} \mathrm{NMR} \delta\left(\mathrm{C}_{6} \mathrm{D}_{6}\right): 23.1\left(\mathrm{bs},{ }^{\mathrm{ecp} 1} \mathrm{CH}_{2}\right), 35.0$ (s, , $\left.{ }^{\text {ecp } 2} \mathrm{CH}_{2}\right), 39.2\left(\mathrm{~s},{ }^{\text {ecp } 4,7} \mathrm{CH}_{2}\right), 39.9$ (s, $\left.{ }^{\text {ccp } 4,7} \mathrm{CH}_{2}\right), 41.1$ (s, $\left.{ }^{\text {ecp } 3} \mathrm{CH}\right)$, $114.6\left(\mathrm{~s},{ }^{\mathrm{mp}}{ }^{5} \mathrm{CH}\right), 125.5\left(\mathrm{~s},{ }^{\mathrm{Ph}} \mathrm{C}\right), 127.2\left(\mathrm{~s},{ }^{\mathrm{Ph}} \mathrm{C}\right), 127.5\left[\mathrm{~d}, J_{\mathrm{PC}}=12.6\right.$ $\left.\mathrm{Hz}, \mathrm{P}\left(\mathrm{C}_{6} \mathrm{H}_{5}\right)_{3}\right], 128.9\left[\mathrm{~d}, J_{\mathrm{PC}}=12.5 \mathrm{~Hz}, \mathrm{P}\left(\mathrm{C}_{6} \mathrm{H}_{5}\right)_{3}\right], 130.3\left(\mathrm{~s},{ }^{\text {ecp } 5,6} \mathrm{C}\right)$, $130.9\left(\mathrm{~d},{ }^{3} J_{\mathrm{RhC}}=3.4 \mathrm{~Hz},{ }^{\mathrm{mp} 3} \mathrm{CH}\right), 133.1\left(\mathrm{~s},{ }^{\mathrm{mp}} \mathrm{CH}\right), 134.8\left(\mathrm{~s},{ }^{\mathrm{Ph}} \mathrm{C}\right)$, $134.9\left[\mathrm{~d}, J_{\mathrm{PC}}=12.4, \mathrm{P}\left(\mathrm{C}_{6} \mathrm{H}_{5}\right)_{3}\right], 135.4\left[\mathrm{~d}, J_{\mathrm{PC}}=11.3 \mathrm{~Hz}, \mathrm{P}\left(\mathrm{C}_{6} \mathrm{H}_{5}\right)_{3}\right]$, $138.2\left[\mathrm{~d},{ }^{1} J_{\mathrm{PC}}=37.0 \mathrm{~Hz}, \mathrm{P}\left(\mathrm{C}_{6} \mathrm{H}_{5}\right)_{3}\right], 143.2\left(\mathrm{~s},{ }^{\mathrm{mp} 6} \mathrm{CH}\right), 145.8(\mathrm{bs}$, assigned through $\left.\mathrm{HMBC},{ }^{i-\mathrm{Ph}} \mathrm{C}\right), 179.1\left(\mathrm{dd},{ }^{2} J_{\mathrm{RhC}}=11.1 \mathrm{~Hz},{ }^{\mathrm{mp} 2} \mathrm{C}\right)$.

Synthesis of $\left[\mathrm{Rh}\left\{\kappa^{2}-\mathrm{S}, \mathrm{D}-\mathrm{HB}(\mathrm{Ph})(\mathrm{mp})\left(\mathrm{CHDCH}_{2} \mathrm{C}_{5} \mathrm{H}_{7}\right)\right\}-\right.$ $\left(\mathbf{P P h}_{3}\right)$ ] (5-d $\mathbf{d}_{2}$. This complex was synthesized in a similar manner to the non-deuterated analogue, Complex 4 , by the addition of $\mathrm{D}_{2}$ to Complex 2 in benzene. ${ }^{2} \mathrm{D}$ NMR $\delta\left(\mathrm{C}_{6} \mathrm{D}_{6}\right):-6.90$ (bs, BD) 0.57 (bs, ${ }^{\text {ecpl }}$ CHD).

Synthesis of $\left[\mathrm{Rh}\left\{\boldsymbol{\kappa}^{2}-\mathrm{S}, \mathrm{H}-\mathrm{HB}(\mathrm{Ph})(\mathrm{mp})\left(\mathrm{CH}_{2} \mathrm{CH}_{2} \mathrm{C}_{5} \mathrm{H}_{7}\right)\right\}(\mathrm{CO})-\right.$ $\left.\left(\mathbf{P P h}_{3}\right)\right]$ (6). A Young's NMR tube was charged with $\left[\mathrm{Rh}\left\{\kappa^{2}-S, H\right.\right.$ $\left.\left.\mathrm{HB}(\mathrm{Ph})(\mathrm{mp})\left(\mathrm{CH}_{2} \mathrm{CH}_{2} \mathrm{C}_{5} \mathrm{H}_{7}\right)\right\}(\mathrm{CO})\left(\mathrm{PPh}_{3}\right)\right] \quad\left(3 \mathrm{mg}, 4.38 \times 0^{-3}\right.$ $\mathrm{mmol}$ ) and dissolved in $0.8 \mathrm{~mL}$ of benzene-d6. The resulting solution was degassed through three consecutive freeze-pump-thaw cycles before the headspace was subsequently filled with $\mathrm{H}_{2}$. The reaction mixture was left to react for 6 days before the NMR of the product was recorded. ${ }^{1} \mathrm{H}$ NMR $\delta\left(\mathrm{C}_{6} \mathrm{D}_{6}\right): 1.58\left(\mathrm{~m}, 1 \mathrm{H},{ }^{\text {ecp } 1} \mathrm{CH}_{2}\right)$, $1.65\left(\mathrm{~m}, 1 \mathrm{H},{ }^{\text {ecp } 2} \mathrm{CH}_{2}\right), 2.09\left(\mathrm{~m}, 1 \mathrm{H},{ }^{\text {ecp }} \mathrm{CH}_{2}\right), 2.15(\mathrm{~m}, 2 \mathrm{H}$, $\left.{ }^{\text {epc } 4,7} \mathrm{CH}_{2}\right), 2.54\left(\mathrm{~m}, 1 \mathrm{H},{ }^{\text {ecp } 3} \mathrm{CH}\right), 2.63\left(\mathrm{~m}, 2 \mathrm{H},{ }^{\mathrm{epc} 4,7} \mathrm{CH}_{2}\right), 5.72(\mathrm{~s}$, $\left.2 \mathrm{H},{ }^{\text {ecp5, }}{ }^{6} \mathrm{CH}\right), 5.95\left(\tau \mathrm{d},{ }^{3} J_{\mathrm{HH}}=6.8 \mathrm{~Hz}, 1 \mathrm{H},{ }^{\mathrm{mp} 5} \mathrm{CH}\right), 6.30\left(\tau \mathrm{d},{ }^{3} J_{\mathrm{HH}}\right.$ $\left.=6.8 \mathrm{~Hz}, 1 \mathrm{H},{ }^{\mathrm{mp} 4} \mathrm{CH}\right), 7.02\left(\mathrm{~m}, 9 \mathrm{H},{ }^{\mathrm{PPh}} \mathrm{CH}\right), 7.24\left(\mathrm{~d}, 1 \mathrm{H},{ }^{\mathrm{mp}}{ }^{3} \mathrm{CH}\right)$, $7.55\left(\mathrm{~m}, 6 \mathrm{H},{ }^{\mathrm{PPh}} \mathrm{CH}\right), 7.65\left(\mathrm{~d}, 1 \mathrm{H},{ }^{\mathrm{mp} 6} \mathrm{CH}\right),{ }^{1} \mathrm{H}\left\{{ }^{11} \mathrm{~B}\right\} \mathrm{NMR} \delta\left(\mathrm{C}_{6} \mathrm{D}_{6}\right)$ : $-3.57\left(\mathrm{dd},{ }^{1} J_{\mathrm{RhH}}=45.5 \mathrm{~Hz},{ }^{3} J_{\mathrm{PH}}=20.6 \mathrm{~Hz}\right) .{ }^{11} \mathrm{~B} \mathrm{NMR} \delta\left(\mathrm{C}_{6} \mathrm{D}_{6}\right)$ : 3.7 (bs, h.h.w. $=440 \mathrm{~Hz}, \mathrm{BH}) .{ }^{11} \mathrm{~B}\left\{{ }^{1} \mathrm{H}\right\} \mathrm{NMR} \delta\left(\mathrm{C}_{6} \mathrm{D}_{6}\right): 3.7$ (bs, h.h.w. $=400 \mathrm{~Hz}, \mathrm{BH}) \cdot{ }^{31} \mathrm{P}\left\{{ }^{1} \mathrm{H}\right\} \mathrm{NMR} \delta\left(\mathrm{C}_{6} \mathrm{D}_{6}\right): 41.8\left(\mathrm{~d},{ }^{1} \mathrm{~J}_{\mathrm{RhP}}=\right.$ $160.4 \mathrm{~Hz}) \cdot{ }^{13} \mathrm{C}\left\{{ }^{1} \mathrm{H}\right\}$ NMR $\delta\left(\mathrm{C}_{6} \mathrm{D}_{6}\right): 24.6\left(\mathrm{bs},{ }^{\text {ecp } 1} \mathrm{CH}_{2}\right), 34.2(\mathrm{~s}$, $\left.{ }^{\text {ecp } 2} \mathrm{CH}_{2}\right), 38.4\left(\mathrm{~s},{ }^{\text {ecp } 4,7} \mathrm{CH}_{2}\right), 38.5\left(\mathrm{~s},{ }^{\text {ecp } 4,7} \mathrm{CH}_{2}\right), 47.8\left(\mathrm{~s},{ }^{\text {ecp } 3} \mathrm{CH}\right)$, 114.9 (s, $\left.{ }^{\mathrm{mp} 5} \mathrm{CH}\right), 127.3$ [unresolved, $\left.\mathrm{P}\left(\mathrm{C}_{6} \mathrm{H}_{5}\right)_{3}\right], 129.0$ [s, $\left.\mathrm{P}\left(\mathrm{C}_{6} \mathrm{H}_{5}\right)_{3}\right], 129.3$ (s, $\left.{ }^{\text {ecp } 5,6} \mathrm{C}\right), 126.3\left(\mathrm{~d},{ }^{\mathrm{mp} 3} \mathrm{CH}\right), 133.1\left(\mathrm{~s},{ }^{\mathrm{mp}} \mathrm{CH}\right)$, $133.5\left[\mathrm{~s}, \mathrm{P}\left(\mathrm{C}_{6} \mathrm{H}_{5}\right)_{3}\right], 142.2\left(\mathrm{~s},{ }^{\mathrm{mp} 6} \mathrm{CH}\right), 177.8\left(\mathrm{~s},{ }^{\mathrm{mp}}{ }^{2} \mathrm{C}\right)$.

\section{Catalytic Investigations}

General procedure for the catalytic hydrogenation of cyclooctene and styrene by complexes 2 and 3. For 5 mol\% catalytic loading using 2 and 3: A Young's NMR tube was charged with complex 2 $\left(3.0 \mathrm{mg}, 3.26 \times 10^{-3} \mathrm{mmol}\right)$ or complex $3\left(3.0 \mathrm{mg}, 4.38 \times 10^{-3}\right.$ $\mathrm{mmol})$ in addition to 1,3,5-trimethoxybenzene $(10.0 \mathrm{mg}, 5.95 \times$ $10^{-2} \mathrm{mmol}$ ) as an internal standard. To complex 2 was added 0.8 $\mathrm{mL}$ of $\mathrm{C}_{6} \mathrm{D}_{6}$ containing cyclooctene $(8.5 \mu \mathrm{L})$ or styrene $(7.3 \mu \mathrm{L})$ and to complex $3,1.0 \mathrm{~mL}$ of $\mathrm{C}_{6} \mathrm{D}_{6}$ containing cyclooctene $(11.4$ $\mu \mathrm{L})$ or styrene $(9.8 \mu \mathrm{L})$. The reaction mixture was degassed through three consecutive freeze-pump-thaw cycles before the headspace was pressurized to 2.0 bar with hydrogen. The NMR tube was heated to $80{ }^{\circ} \mathrm{C}$ for $18 \mathrm{~h}$. The conversion from the olefin to the hydrogenated product was determined by peak integrals relative to the internal standard (1,3,5-trimethoxybenzene). A similar approach was adopted for $1 \mathrm{~mol} \%$ catalytic loading using $\mathbf{2}$ and $\mathbf{3}$ : Complex $2\left(0.6 \mathrm{mg}, 6.52 \times 10^{-4} \mathrm{mmol}\right)$ or complex $3(3.0 \mathrm{mg}, 8.76$ $\left.\times 10^{-4} \mathrm{mmol}\right)$ in addition to $1,3,5$-trimethoxybenzene $(10.0 \mathrm{mg}$, $5.95 \times 10^{-2} \mathrm{mmol}$ ) was added to a Young's NMR tube. To complex 2 was added $0.8 \mathrm{~mL}$ of $\mathrm{C}_{6} \mathrm{D}_{6}$ containing cyclooctene $(8.5 \mu \mathrm{L})$ or styrene $(7.3 \mu \mathrm{L})$ and to Complex $3,1.0 \mathrm{~mL}$ of $\mathrm{C}_{6} \mathrm{D}_{6}$ containing cyclooctene $(11.4 \mu \mathrm{L})$ or styrene $(9.8 \mu \mathrm{L})$. For $0.1 \mathrm{~mol} \%$ catalytic loading of 2 and 3: Complex 2 (3.0 mg, $3.26 \times 10^{-3} \mathrm{mmol}$ ) or complex 3 (3.0 mg, $\left.4.38 \times 10^{-3} \mathrm{mmol}\right)$ in addition to 1,3,5-trimethoxybenzene $\left(10.0 \mathrm{mg}, 5.95 \times 10^{-2} \mathrm{mmol}\right)$ was added to a Young's NMR tube. To complex 2 was added $0.8 \mathrm{~mL}$ of $\mathrm{C}_{6} \mathrm{D}_{6}$ containing cyclooctene $(85 \mu \mathrm{L})$ or styrene $(73 \mu \mathrm{L})$ and to complex $3,1.0 \mathrm{~mL}$ of $\mathrm{C}_{6} \mathrm{D}_{6}$ containing cyclooctene $(114 \mu \mathrm{L})$ or styrene $(98 \mu \mathrm{L})$. Hydrogen, at 2.0 bar pressure, was added after degassing and the NMR tube was heated to $80^{\circ} \mathrm{C}$ for $18 \mathrm{~h}$. The conversion from the olefin to the hydrogenated product was determined by peak integrals relative to the internal standard (1,3,5-trimethoxybenzene).

\section{Crystallography}

Single-crystal X-ray diffraction studies of complexes 1, 2, 3 and 7 were carried out at the UK National Crystallography Service at the University of Southampton. ${ }^{31}$ Single crystals of the complexes $\mathbf{1}$ and $\mathbf{3}$ were obtained by allowing a saturated ether solution stand at room temperature, while those of $\mathbf{2}$ were prepared from a saturated solution of the complex dissolved in acetone. Single crystals of 7 were obtained by allowing a diethyl ether solution of $\left[\mathrm{Rh}\left(\kappa^{2}-\right.\right.$ H,S-HB(Ph) $\left.\left.\left(\mathrm{CH}_{2} \mathrm{CH}_{2} \mathrm{C}_{5} \mathrm{H}_{7}\right)(\mathrm{mp})\right\}\left(\mathrm{PPh}_{3}\right)_{2}\right]$ (5) for several days. A single crystal from each sample was mounted on a MITIGEN holder in perfluoroether oil on a Rigaku FRE+ Mo anode equipped with HF Varimax confocal mirrors and an $\mathrm{AFC1} 12$ goniometer and HG Saturn 724+ detector $(\mathbf{1}, 2)$ or HyPix 6000 hybrid pixel detector (3) or a Rigaku 007HF Cu anode equipped with Varimax confocal mirrors and an AFC11 goniometer and HyPix 6000 hybrid pixel detector (7) The crystals were kept at $\mathrm{T}=100(2) \mathrm{K}$ during data collection. Data were collected and processed and empirical absorption corrections were carried out using CrysAlisPro. ${ }^{32}$ The structures were solved by Intrinsic Phasing using the ShelXT structure solution program ${ }^{33}$ and refined on $F_{o}^{2}$ by full-matrix least squares refinement with version $2017 / 1$ of ShelXL for complexes $\mathbf{1}$ and $\mathbf{2}$ and version $2018 / 3$ for complex $\mathbf{3}^{34}$ as implemented in Olex2. ${ }^{35}$ All hydrogen atom positions were calculated geometrically and refined using the riding model with the following exceptions. In the structures of $\mathbf{1}$ and 7, H1 A and H1B bonded to B1 were located in the difference map and were refined with the riding model and their positions allowed to freely refine. In structure $\mathbf{2}$, one of the triphenylphosphine ligands is disordered over two positions (ca. 50:50). Also, one of the solvent acetone molecules is disordered over two positions (ca. 50:50). Structure 7 solved as a nonmerohedral twin with the second component rotated by $179.9117^{\circ}$ about the b-axis. A summary of the crystallographic data collection parameters and refinement details for all complexes are presented in the table below. Anisotropic parameters, bond lengths and (torsion) angles for these structures are available from the CIF files which have been deposited with the Cambridge Crystallographic Data Centre and given the following deposition numbers, 1955411 (1), 1955412 (2), 1955413 (3) and 1955414 (7). These data can be 
obtained free of charge from The Cambridge Crystallographic Data Centre via www.ccdc.cam.ac.uk/data_request/cif.

\section{ASSOCIATED CONTENT}

Supporting Information. Crystallographic parameters for all crystal structures in addition to selected spectroscopic data are provided in the Electronic Supporting Information. This material is available free of charge via the Internet at http://pubs.acs.org.

\section{AUTHOR INFORMATION}

\section{Corresponding Author}

Dr. Gareth R. Owen, School of Applied Science, University of South Wales, Treforest, United Kingdom, CF37 4AT, E-mail: gareth.owen@southwales.ac.uk

\section{Author Contributions}

The manuscript was written through contributions of all authors. All authors have given approval to the final version of the manuscript.

\section{Notes}

The authors declare no competing financial interest.

\section{ACKNOWLEDGMENT}

The authors would like to thank the Leverhulme Trust (PRG-2015097) for funding (RCDC, GRO). The project is also part funded by the FLEXIS research project (WEFO 80835). We are also very grateful to the EPSRC UK National Mass Spectrometry Facility (NMSF) at Swansea University and to Johnson Matthey for the loan of the platinum group metal salts.

\section{REFERENCES}

(1a) Milstein, D.; Khusnutdinova J. R. Metal-Ligand Cooperation Angew. Chem. Int. Ed. 2015, 54, 12236-12273. (1b) Hou, C.; Zhang, Z.; Zhao, C.; Ke, Z. DFT Study of Acceptorless Alcohol Dehydrogenation Mediated by Ruthenium Pincer Complexes: Ligand Tautomerization Governing Metal Ligand Cooperation. Inorg. Chem. 2016, 55, 6539-6551. (1c) Wodrich, M. D.; Hu, X. Natural inspirations for metal-ligand cooperative catalysis. Nat. Rev. Chem. 2017, 2, 0099. (1d) Li, H.; Gonçalves, T. P.; Lupp, D.; Huang, K.-W. PN 3 (P)-Pincer Complexes: Cooperative Catalysis and Beyond. ACS Catal. 2019, 9, 1619-1629. (1e) Bullock, R. M.; Chambers, G. M. Frustration across the periodic table: heterolytic cleavage of dihydrogen by metal complexes. Phil. Trans. R. Soc. A. 2017, 375, 20170002. (1f) Guan, W.; Zeng, G.; Kameo, H.; Nakao, Y.; Sakaki, S. Cooperative Catalysis of Combined Systems of Transition-Metal Complexes with Lewis Acids: Theoretical Understanding. Chem. Rec. 2016, 16, 2405-2425.

(2a) Kameo, H. and Nakazawa, H. Recent Developments in the Coordination Chemistry of Multidentate Ligands Featuring a Boron Moiety. Chem. - Asian J. 2013, 8, 1720-1734. (2b) Bouhadir, G.; Bourissou, D. Complexes of ambiphilic ligands: reactivity and catalytic applications. Chem. Soc. Rev. 2016, 45, 1065-1079. (2c) Owen, G. R. Functional group migrations between boron and metal centres within transition metal-borane and -boryl complexes and cleavage of $\mathrm{H}-\mathrm{H}$, E-H and E-E' bonds. Chem. Commun. 2016, 52, 10712-10726. (2d) Devillard, M.; Bouhadir, G.; Bourissou, D. Cooperation between Transition Metals and Lewis Acids: A Way To Activate $\mathrm{H}_{2}$ and $\mathrm{H}-\mathrm{E}$ bonds. Angew. Chem. Int. Ed. 2015, 54, 730-732. (2e) Owen, G. R. Hydrogen atom storage upon Z-class borane ligand functions: an alternative approach to ligand cooperation. Chem. Soc. Rev. 2012, 41, 3535-3546. (2f) Tsoureas, N.; Hamilton, A.; Haddow, M. F.; Harvey, J. N.; Orpen, A. G.; Owen, G. R. Insight into the Hydrogen Migration Processes Involved in the Formation of Metal-Borane Complexes: Importance of the Third Arm of the Scorpionate Ligand. Organometallics 2013, 32, $2840-2856$
(3) Neshat, A.; Shahsavari, H. R.; Mastrorilli, P.; Todisco, S.; Haghighi, M. G.; Notash, B. A. Borane Platinum Complex Undergoing Reversible Hydride Migration in Solution. Inorg. Chem. 2018, 57, 1398-1407.

(4a) Rudolf, G. C.; Hamilton, A.; Orpen, A. G.; Owen, G. R. A 'sting' on Grubbs' catalyst: an insight into hydride migration between boron and a transition metal. Chem. Commun. 2009, 553-555. (4b) Lee, H.; Jordan, R. F. Unusual Reactivity of Tris(pyrazolyl)borate Zirconium Benzyl Complexes. J. Am. Chem. Soc. 2005, 127, 9384-9385. (4c) Fischbach, A.; Bazinet, P. R.; Waterman, R.; Tilley, T. D. $\beta$-Phosphinoethylboranes as Ambiphilic Ligands in Nickel-Methyl Complexes. Organometallics 2008, 27, 1135-1139. (4d) Fromel, S.; Kehr, G.; Fröhlich, R.; Daniliuc, C. G.; Erker, G. Reactions of dimethylzirconocene complexes with a vicinal frustrated P/B Lewis pair. Dalton Trans. 2013, 42, 14531-14536. (4e) Eleazer, B. J.; Smith, M. D.; Peryshkov, D. V. Metal- and Ligand-Centered Reactivity of meta-Carboranyl-Backbone Pincer Complexes of Rhodium. Organometallics 2016, 35, 106-112. (4f) Pal, S.; Vedernikov, A. N. Oxidation of dimethyldi(2-pyridyl)borato $\mathrm{Pt}^{\mathrm{II}} \mathrm{Me}_{\mathrm{n}}$ complexes, $\mathrm{n}=1$, 0 , with $\mathrm{H}_{2} \mathrm{O}_{2}$ : tandem B-to-Pt methyl group migration and formation of $\mathrm{C}-\mathrm{O}$ bond. Dalton Trans. 2012, 41, 8116-8122. (4g) Zhu, J.; Mukherjee, D.; Sadow, A. D. Abstraction of $\beta$-hydrogen vs. alkyl groups in reactions of dialkylzinc compounds and bis(oxazolinyl)borane. Chem. Commun. 2012, 48 , 464-466. (4h) Cowie, B. E.; Emslie, D. J. H. Bis-hydrocarbyl Platinum(II) Ambiphilic Ligand Complexes: Alkyl-Aryl Exchange between Platinum and Boron. Organometallics 2015, 34, 2737-2746. (4i) Cowie, B. E.; Emslie, D. J. H. Bridging Rhodium-Iron Borataaminocarbyne Complexes Formed by Intramolecular Isonitrile-Borane Coordination. Organometallics 2013, 32, 7297-7305. (4j) Shih, W.-C.; Gu, W.; MacInnis, M. C.; Timpa, S. D.; Bhuvanesh, N.; Zhou, J.; Ozerov, O. V. Facile Insertion of Rh and Ir into a Boron-Phenyl Bond, Leading to Boryl/Bis(phosphine) PBP Pincer Complexes. $J$. Am. Chem. Soc. 2016, 138, 2086-2089. (4k) Bajo, S.; Esteruelas, M. A.; Lopez, A. M.; Oñate, E. Osmium-Acyl Decarbonylation Promoted by Tp-Mediated Allenylidene Abstraction: A New Role of the Tp Ligand. Organometallics 2014, 33, 4057-4066. (41) Shih, W.-C.; Gu, W.; MacInnis, M. C.; Herbert, D. E.; Ozerov, O. V. Boryl/Borane Interconversion and Diversity of Binding Modes of Oxygenous Ligands in PBP Pincer Complexes of Rhodium. Organometallics 2017, 36, 17181726.

(5) Iannetelli, A.; Tizzard, G. J.; Coles, S. J.; Owen, G. R. Sequential Migrations between Boron and Rhodium Centers: A Cooperative Process between Rhodium and a Monosubstituted Borohydride Unit. Inorg. Chem. 2018, 57, 446-456.

(6) Owen, G. R.; Tsoureas, N.; Hope, R. F. Kuo Y.-Y.; Haddow, M. F. Synthesis and characterisation of group nine transition metal complexes containing new mesityl and naphthyl based azaindole scorpionate ligands. Dalton Trans. 2011, 40, 5906-5915.

(7) Tsoureas, N.; Owen, G. R.; Hamilton A.; Orpen, A. G. Flexible scorpionates for transfer hydrogenation: the first example of their catalytic application. Dalton Trans. 2008, 6039-6044.

(8a) Marks, T. J.; Kolb, J. R. Covalent transition metal, lanthanide, and actinide tetrahydroborate complexes. Chem. Rev. 1977, 77, 263 293. (8b) Westcott, S. A.; Marder, T. B.; Baker, R. T.; Harlow, R. L.; Calabrese, J. C.; Lam, K. C.; Lin, Z. Reactions of hydroborating reagents with phosphinorhodium hydride complexes: molecular structures of a $\mathrm{Rh}_{2} \mathrm{~B}_{3}$ metallaborane cluster, an $\mathrm{L}_{2} \mathrm{Rh}\left(\mathrm{\eta}^{2}-\mathrm{H}_{2} \mathrm{BR}_{2}\right)$ complex and a mixed valence $\mathrm{Rh}$ dimer containing a semi-bridging Bcat (cat $=1,2$ $\mathrm{O}_{2} \mathrm{C}_{6} \mathrm{H}_{4}$ ) group. Polyhedron 2004, 23, 2665-2677. (8c) Besora, M; Lledós, A. Coordination Modes and Hydride Exchange Dynamics in Transition Metal Tetrahydroborate Complexes. In: Marder T.B., Lin Z. (eds) Contemporary Metal Boron Chemistry I. Structure and Bonding, 2008, 130, 149, Springer, Berlin, Heidelberg.

(9a) Brugos, J.; Cabeza, J. A.; García-Álvarez, P.; Kennedy, A. R.; Pérez-Carreño, E.; Van der Maelen, J. F. 2-(Methylamido)pyridine-Borane: A Tripod $\kappa^{3}-N, H, H$ Ligand in Trigonal Bipyramidal Rhodium(I) and Iridium(I) Complexes with an Asymmetric Coordination of Its $\mathrm{BH}_{3}$ Group. Inorg. Chem. 2016, 55, 8905-8912. (9b) Blug, M.; Grunstein, D.; Alcaraz, G.; Sabo-Etienne, S.; Le Goff, X.-F.; Le Floch, P.; Mezailles, N. Bonding mode of a new bis-phosphine-borane alkyl ligand to a $\mathrm{Rh}(\mathrm{I})$ species. Chem. Commun. 2009, 4432-4434. (9c) 
Drover, M. W.; Bowes, E. G.; Love, J. A.; Schafer, L. L.e. Accessing $\delta$-B-H Coordinated Complexes of $\mathrm{Rh}(\mathrm{I})$ and $\operatorname{Ir}(\mathrm{I})$ Using Mono- and Dihydroboranes: Cooperative Stabilization by a Phosphoramidate Coligand. Organometallics 2017, 36, 331-341. (9d) Nguyen, D. H.; Lauréano, H.; Jugé, S.; Kalck, P.; Daran, J.-C.; Coppel, Y.; Urrutigoity, M.; Gouygou, M. First Dibenzophospholyl(diphenylphosphino)methaneBorane Hybrid P- $\left(\eta^{2}-\mathrm{BH}_{3}\right)$ Ligand: Synthesis and Rhodium(I) Complex. Organometallics 2009, 28, 6288-6292.

(10) The spectroscopic data for this product was extremely broad, presumably due to fluxional coordination of the $\mathrm{CO}$ ligands. The ${ }^{1} \mathrm{H}$ NMR however did show signs of free norbornadiene. On this basis, we suspect a straightforward ligand substitution reaction has occurred in this case.

(11) Reaction of complex 1 with one equivalent of triphenylphosphine led to a 1:1 mixture of starting material and complex $\mathbf{2}$ as determined by NMR spectroscopy. No other species were observed by NMR spectroscopy.

(12) One of these carbon signals was extremely broad and difficult to distinguish from the baseline of the spectrum. This was later identified and assigned as the carbon adjacent to the quadrupolar boron.

(13a) Xu, S.; Haeffner, F.; Li, B.; Zakharov, L. N.; Liu, S.-Y. Monobenzofused 1,4-Azaborines: Synthesis, Characterization, and Discovery of a Unique Coordination Mode. Angew. Chem. Int. Ed. 2014, 53 , 6795-6799. (13b) Xu, S.; Zhang, Y.; Li, B.; Liu, S.-Y. Site-Selective and Stereoselective trans-Hydroboration of 1,3-Enynes Catalyzed by 1,4-Azaborine-Based Phosphine-Pd Complex. J. Am. Chem. Soc. 2016, 138, 14566-14569. (13c) Yang, Y.; Jiang, J.; Yu, H.; Shi, J. Mechanism and Origin of the Stereoselectivity in the Palladium-Catalyzed trans Hydroboration of Internal 1,3-Enynes with an AzaborineBased Phosphine Ligand. Chem. Eur. J. 2018, 24, 178-186.

(14a) Chiu, C.W.; Gabbaï, F. P. Structural Change Accompanying the Stepwise Population of a BC $\pi$ Bond. Angew. Chem. Int. Ed. 2007, 46, 6878-6881. (14b) Möbus, J.; Kehr, G.; Daniluc, C. G.; Fröhlich, R.; Erker G. Borata-alkene derivatives conveniently made by frustrated Lewis pair chemistry. Dalton Trans. 2014, 43, 632-638.

(15a) Emslie, D. J. H.; Cowie, B. E.; Kolpin, K. B. Acyclic BoronContaining p-Ligand Complexes: $\eta^{2}$ - and $\eta^{3}$-Coordination Modes. Dalton Trans. 2012, 41, 1101-1117. (15b) Braunschweig, H.; Ye, Q.; Celik, M. A.; Dewhurst, R. D.; Radacki, K. Cyclization of a 1,4-Diborabutadiene Ligand with Both Atoms of CO. Angew. Chem. Int. Ed. 2015, 54, 5065-5068. (15c) Braunschweig, H.; Brenner, P.; Dewhurst, R. D.; Krummenacher, I.; Pfaffinger, B.; Vargas, A. Unsupported boron-carbon $\sigma$-coordination to platinum as an isolable snapshot of $\sigma$ bond activation. Nat. Commun. 2012, 3, 872-877.

(16) Oakley, S. R.; Parker, K. D.; Emslie, D. J. H.; Vargas-Baca, I.; Robertson, C. M.; Harrington, L. E.; Britten, J. F. Synthesis of a Heterobimetallic Rhodium-Iron Complex Containing an $\eta^{3}$-Interaction between Rhodium and the $\mathrm{B}-\mathrm{C}_{\mathrm{ipso}}-\mathrm{C}_{\text {ortho }}$ Unit of a Triarylborane. Organometallics 2006, 25, 5835-5838.

(17) Dyson, G.; Zech, A.; Rawe, B. W.; Haddow, M. F.; Hamilton, A. Scorpionate Ligands Based on 2-Mercaptopyridine: A Ligand with a Greater Propensity To Sting? Organometallics 2011, 30, 5844-5850.

(18) Goodman, J.; Grushin, V. V.; Larichev, R. B.; Macgregor, S. A.; Marshall, W. J.; Roe, D. C.; Fluxionality of $\left[\left(\mathrm{Ph}_{3} \mathrm{P}\right)_{3} \mathrm{M}(\mathrm{X})\right](\mathrm{M}=$ $\mathrm{Rh}, \mathrm{Ir})$. The Red and Orange Forms of $\left[\left(\mathrm{Ph}_{3} \mathrm{P}\right)_{3} \operatorname{Ir}(\mathrm{Cl})\right]$. Which Phosphine Dissociates Faster from Wilkinson's Catalyst? J. Am. Chem. Soc. 2010, 132, 12013-12026.

(19) Owen, G. R. Crystal field arguments to explain the trans labilisation within transition metal-borane complexes. Trans. Met. Chem. 2009, 35, 221-228.

(20) Heating 2 for prolonged periods of time led to the formation of a mixture of species with one main product most evident in the ${ }^{31} \mathrm{P}\left\{{ }^{1} \mathrm{H}\right\}$ spectra $\left[57.1 \mathrm{ppm}\left({ }^{1} \mathrm{~J}_{\mathrm{RhP}}=180 \mathrm{~Hz},{ }^{2} \mathrm{~J}_{\mathrm{PP}}=43 \mathrm{~Hz}\right)\right.$ and $43.3 \mathrm{ppm}\left({ }^{1} \mathrm{~J}_{\mathrm{RhP}}=\right.$ $\left.\left.178 \mathrm{~Hz},{ }^{2} \mathrm{~J}_{\mathrm{PP}}=43 \mathrm{~Hz}\right)\right]$. Unfortunately, we were unable to isolate this species since it decomposed before full conversion. ${ }^{1} \mathrm{H}$ NMR spectroscopy suggested that the organic fragment had been lost and so this line of investigation was not pursued further.

(21a) Jia, G.; Lin, Z.; Lau, C. P. Reactions of Dihydrogen(norbornadiene)Complexes. Eur. J. Inorg. Chem. 2003, 2003, 2551-2562. (21b) Tsoureas, N.; Bevis, T.; Butts, C. P.; Hamilton, A.; Owen, G. R. Further
Exploring the "Sting of the Scorpion": Hydride Migration and Subsequent Rearrangement of Norbornadiene to Nortricyclyl on Rhodium(I). Organometallics 2009, 28, 5222-5232.

(22a) Mail, R. E.; Garralda, M. A.; Hernández, R.; Ibarlucea, L.; Pinilla, E.; Torres, M. R.; Zarandona, M. Nortricyclyl- and Norbornenyl-Acylrhodium Complexes from the Reaction of Norbornadiene Rhodium(I) Complexes with $o$-(Diphenylphosphanyl)benzaldehyde. Eur. J. Inorg. Chem. 2005, 1671-1677. (22b) Azpeitia, S.; Barquín, M.; Mendicute-Fierro, C.; Huertos, M. A.; Rodríguez-Diéguez, A.; Seco, J. M.; Sebastian, E. S.; Ibarlucea, L.; Garralda, M. A. (Diphenylphosphino)alkylaldehyde affords hydride- or alkyl-[(diphenylphosphino)alkylacyl]rhodium(III) or (diphenylphosphino)alkylester complexes: theoretical and experimental diastereoselectivity. Dalton Trans. 2019, 48, 3300-3313. (22c) Almenara, N.; Ibarlucea, L., Mendicute-Fierro, C.; Seco, J. M.; Rodríguez-Diéguez, A.; Garralda, M. A.; Huertos, M. A. A pentacoordinated norbornenyl-acyl-rhodium(III) complex as a likely intermediate in the catalytic hydroacylation of norbornadiene. Dalton Trans. 2016, 45, 18502-18509. (22d) Barquín, M.; Garralda, M. A.; Ibarlucea, L.; Mendicute-Fierro, C.; Pinilla, E.; Nacianceno, V. S.; Torre, M. R. Formation of New $\sigma$-Norbornenylrhodium(III) Complexes Promoted by Quinoline-8-carbaldehyde and Their Rearrangement into Nortricyclylrhodium(III) Derivatives. Formation of Norbornene and Nortricyclene. Organometallics 2011, 30, 1577-1587. (22e) Mata, J. A.; Peris, E.; Incarvito, C.; Crabtree, R. H. A methylene-bis-triazolium ligand precursor in an unusual rearrangement of norbornadiene to nortricyclyl. Chem. Commun. 2003, 184-185. (22f) Dotra, R.; Konstantinovski, L.; Shimon, L. J. W.; BenDavid, Y.; Milstein, D. Chelation versus Cyclometalation in a Cationic Dppn- $\mathrm{Rh}^{\mathrm{I}}$ Complex - A Unique Rearrangement of Norbornadiene via $\mathrm{C}-\mathrm{H}$ Activation of the Pyridazine Ring. Eur. J. Inorg. Chem. 2003, 2003, 70-76. (22g) Trauthwein, H.; Tillack, A.; Beller, M. New rhodium-catalyzed amination reactions. Chem. Commun. 1999, 2029 2030.

(23) The complex $\left[\mathrm{Rh}\left\{\kappa^{3}-H, H, S-\mathrm{H}_{2} \mathrm{~B}(\mathrm{Ph})(\mathrm{mp})\right\}\left(\mathrm{PPh}_{3}\right)_{2}\right]$ (4), can be prepared in situ via the reaction of $\left[\mathrm{Rh}\left\{\kappa^{3}-H, H, S\right.\right.$ $\left.\left.\mathrm{H}_{2} \mathrm{~B}(\mathrm{Ph})(\mathrm{mp})\right\}(\mathrm{COD})\right]$ with two equivalents of $\mathrm{PPh}_{3}$. This is currently being explored in more detail and will be reported in a later publication.

(24a) Cowie, B. E.; Emslie, D. J. H. M-H-BR 3 and M-Br-BR 3 Interactions in Rhodium and Nickel Complexes of an Ambiphilic Phosphine-Thioether-Borane Ligand. Can. J. Chem. 2018, 96, 484-491. (24b) Johnson, A.; Martínez-Martínez, A. J.; Macgregor, S. A.; Weller, A. S. $\mathrm{A} \mathrm{d}^{10} \mathrm{Ag}(\mathrm{I})$ amine-borane $\sigma$-complex and comparison with a $\mathrm{d}^{8}$ $\mathrm{Rh}(\mathrm{I})$ analogue: structures on the $\eta^{1}$ to $\eta^{2}: \eta^{2}$ continuum. Dalton Trans. 2019, 48, 9776-9781.

(25) It should be noted that a different reactivity was observed with the parent ligand complex. The reaction of $\left[\mathrm{Rh}\left\{\kappa^{3}-H, H, S\right.\right.$ $\left.\left.\mathrm{H}_{3} \mathrm{~B}(\mathrm{mp})\right\}(\mathrm{NBD})\right]$ with two equivalents of triphenylphosphine resulted in decomposition and the formation of rhodium black within $15 \mathrm{~min}$.

(26a) Tsoureas, N.; Kuo, Y.-Y.; Haddow, M. F.; Owen, G. R. Double addition of $\mathrm{H}_{2}$ to transition metal-borane complexes: a 'hydride shuttle' process between boron and transition metal centres. Chem. Commun. 2011, 47, 484-486. (26b) Harman, W. H.; Peters, J. C. Reversible $\mathrm{H}_{2}$ Addition across a Nickel-Borane Unit as a Promising Strategy for Catalysis. J. Am. Chem. Soc. 2012, 134, 5080-5082.

(27) The crystal structure of the corresponding iridium complexes has previously been reported see: Mura, P.; Robinson, S. D. Structure of cis-Dihydro(2-pyridinethiolato)bis(triphenylphosphine)iridium(III),

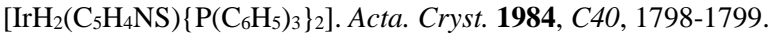

(28a) Douglas, T. M.; Chaplin, A. B.; Weller, A. S.; Yang, X.; Hall, M. B. Monomeric and Oligomeric Amine-Borane $\sigma$-Complexes of Rhodium. Intermediates in the Catalytic Dehydrogenation of Amine-Boranes. J. Am. Chem. Soc. 2009, 131, 15440-15456. (28b) Rossin, A. and Peruzzini, M. Ammonia-Borane and Amine-Borane Dehydrogenation Mediated by Complex Metal Hydrides. Chem. Rev. 2016, 116, 8848-8872. (28c) Adams, G. M.; Ryan, D. E.; Beattie, N. A.; McKay, A. I.; Lloyd-Jones, G. C.; Weller, A. S. Dehydropolymerization of $\mathrm{H}_{3} \mathrm{~B} \cdot \mathrm{NMeH}_{2}$ Using a $[\mathrm{Rh}(\mathrm{DPEphos})]^{+}$Catalyst: The Promoting Effect of $\mathrm{NMeH}_{2}$. ACS Catal. 2019, 94, 3657-3666.

(29) The conversion of $\mathbf{3}$ to $\mathbf{6}$ was much slower. This took $8 \mathrm{~d}$ using 4 equivalents of the amine-borane. 
(30) Abel, E. W.; Bennett, M. A.; Wilkinson, G. NorbornadieneMetal Complexes and Some Related compounds. J. Chem. Soc. 1959 , $3178-3182$

(31) Coles, S. J.; Gale, P. A. Changing and challenging times for service crystallography. Chem. Sci. 2012, 3, 683 .

(32) CrysAlisPro Software System, Rigaku Oxford Diffraction, 2017 (complexes 1 and 2) and 2018 (complex 3 and 7).
(33) Sheldrick, G. M. SHELXT - Integrated space-group and crystal structure determination. Acta Cryst. 2015, A71, 3-8.

(34) Sheldrick, G.M., Crystal structure refinement with ShelXL, Acta Cryst., 2015, C27, 3-8.

(35) Dolomanov, O. V.; Bourhis, L. J.; Gildea, R.J.; Howard, J.A.K.; Puschmann, H. OLEX2: a complete structure solution, refinement and analysis program. J. Appl. Cryst. 2009, 42, 339-341.

\section{For Table of Contents Only}

The syntheses of complexes containing a new substituted borohydride ligand is presented. Reactivity studies show the conversion of norbornadiene into an ethylenyl-cyclopentene unit via cooperation between the boron and metal centers. A novel $\eta^{2}-\mathrm{B}, \mathrm{C}$ unit is formed which activates $\mathrm{H}-\mathrm{H}$ bonds and act as a (de)hydrogenation catalyst.

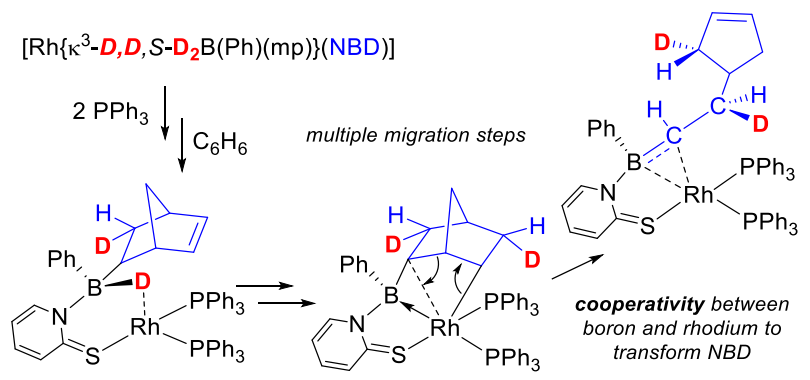

